\title{
Solvate formation of bis(demethoxy)curcumin:
}

\section{Crystal structure analyses and stability investigations}

Lina Yuan, ${ }^{a}{ }^{*}$ Elena Horosanskaia, ${ }^{a}$ Felix Engelhardt,${ }^{b}$ Frank T. Edelmann, ${ }^{b}$ Nicolas Couvrat,${ }^{c}$ Morgane Sanselme, ${ }^{c}$ Yohann Cartigny, ${ }^{c}$ Gérard Coquerel, ${ }^{c}$ Andreas Seidel-Morgenstern, ${ }^{a}$ and Heike Lorenz ${ }^{a}$

${ }^{a}$ Max Planck Institute for Dynamics of Complex Technical Systems, 39106 Magdeburg, Germany

b Chemisches Institut der Otto-von-Guericke-Universität Magdeburg, Universitätsplatz 2, 39106 Magdeburg, Germany

c EA3233, Laboratoire Sciences et Méthodes Séparatives, Normandie Université, UNIROUENNormandie, 76821 Mont Saint Aignan, France

\begin{abstract}
Bis(demethoxy)curcumin (BDMC), extracted from rhizomes of the traditional herb Curcuma longa, has revealed a wide range of medicinal applications, such as antimicrobial and anticarcinogenic. Pure BDMC was obtained by recrystallization from ethanol and three BDMC solvates were identified with acetone, methanol and isopropanol. The crystal structures of pure $\mathrm{BDMC}$ and the solvates were resolved by single crystal X-ray diffraction. Analyses of the crystal structures and calculations of crystal packing efficiencies revealed that pure BDMC is efficiently packed. The solvents involved are not utilized to fill the void spaces in the crystal structures, but to provide effective intermolecular interactions. The stoichiometry of the three solvates obtained from single crystal data is $1: 1$, which is in good agreement with the gravimetric analyses. Furthermore, the desolvation process and stability of the solvates were investigated by various analytical techniques including X-ray diffraction, differential scanning calorimetry, thermogravimetric analyses, hot-stage microscopy and dynamic vapor sorption. Results show that the methanol solvate is more stable compared to the acetone and isopropanol solvates attributed to the strong hydrogen bonding network. Moreover, the desolvation process of the three solvates proceeds through a destructive-reconstructive mechanism.
\end{abstract}




\section{Solvate formation of bis(demethoxy)curcumin:}

\section{Crystal structure analyses and stability investigations}

Lina Yuan, ${ }^{a}{ }^{*}$ Elena Horosanskaia, ${ }^{a}$ Felix Engelhardt ${ }^{b}$ Frank T. Edelmann, ${ }^{b}$ Nicolas Couvrat ${ }^{c}$ Morgane Sanselme, ${ }^{c}$ Yohann Cartigny, ${ }^{c}$ Gérard Coquerel, ${ }^{c}$ Andreas Seidel-Morgenstern, ${ }^{a}$ and Heike Lorenz $^{a}$

${ }^{a}$ Max Planck Institute for Dynamics of Complex Technical Systems, 39106 Magdeburg, Germany

b Chemisches Institut der Otto-von-Guericke-Universität Magdeburg, Universitätsplatz 2, 39106 Magdeburg, Germany

c EA3233, Laboratoire Sciences et Méthodes Séparatives, Normandie Université, UNIROUENNormandie, 76821 Mont Saint Aignan, France 


\section{ABSTRACT}

Bis(demethoxy)curcumin (BDMC), extracted from rhizomes of the traditional herb Curcuma longa, has revealed a wide range of medicinal applications, such as antimicrobial and anticarcinogenic. Pure BDMC was obtained by recrystallization from ethanol and three BDMC solvates were identified with acetone, methanol and isopropanol. The crystal structures of pure $\mathrm{BDMC}$ and the solvates were resolved by single crystal X-ray diffraction. Analyses of the crystal structures and calculations of crystal packing efficiencies revealed that pure BDMC is efficiently packed. The solvents involved are not utilized to fill the void spaces in the crystal structures, but to provide effective intermolecular interactions. The stoichiometry of the three solvates obtained from single crystal data is $1: 1$, which is in good agreement with the gravimetric analyses. Furthermore, the desolvation process and stability of the solvates were investigated by various analytical techniques including X-ray diffraction, differential scanning calorimetry, thermogravimetric analyses, hot-stage microscopy and dynamic vapor sorption. Results show that the methanol solvate is more stable compared to the acetone and isopropanol solvates attributed to the stronger hydrogen bonding network. Moreover, the desolvation process of the three solvates proceeds through a destructive-reconstructive mechanism.

\section{INTRODUCTION}

Solid state forms of Active Pharmaceutical Ingredients (APIs) encompass polymorphs, solvates (including hydrates), salts, co-crystals, solid solutions and amorphous solids. These different

phases have different properties, such as solubility, dissolution rate and bioavailability ${ }^{1}$. The chemical and physical properties of APIs could be significantly improved by developing new solid forms ${ }^{2-4}$. Since solvents are unavoidably used during processing, manufacturing or storage 
of APIs, the investigation of solvate formation deserves particular attention ${ }^{5,6}$. Additionally, the solvate formation property could be used as a method of purification ${ }^{7-9}$. Moreover, desolvation of solvates could be an option to prepare new polymorphic forms, which might be inaccessible by the conventional crystallization methods ${ }^{10-13}$. Despite their advantages, solvates could show an efflorescent character when exposed to ambient conditions ${ }^{14}$. Therefore, stability studies are essential for the successful use of solvates. Furthermore, a fundamental understanding of the reasons for solvate formation is necessary in order to enable the prediction of their formation and stability $^{15}$. Two main scenarios could be envisaged ${ }^{16}$. (i) Potential intermolecular interactions, such as hydrogen bonding, are insufficient in the desolvated form. Thus, the incorporation of solvent molecules will provide stronger intermolecular interactions. (ii) Solvents included in the crystals could reduce void spaces in the crystal structures. In most cases, both of the two driving forces are responsible to the solvate formation. This can be viewed primarily as lowering the crystal free energy by van der Waals and electrostatic interactions.

Natural products have been playing a significant role as the sources of pharmaceutical drugs for thousands of years. In the past twenty years, around half of the approved drugs are based on natural compounds ${ }^{17,18}$. Prominent examples are curcuminoids, extracted from rhizomes of the traditional herb Curcuma longa (commonly known as turmeric). Curcuminoids have a wide range of bioactivities, including antimicrobial, anti-inflammatory, anticarcinogenic and antioxidant properties. Commercially available curcuminoids are mixtures of three structurally similar components: curcumin (CUR), demethoxycurcumin (DMC) and bis(demethoxy)curcumin (BDMC), which makes the purification quite challenging (issue 1) ${ }^{19,20}$. CUR is often considered to be the most active compound which is responsible for the biological activities of curcuminoids ${ }^{21,22}$. Recently, researchers found that BDMC could be a better 
cytotoxic agent than curcumin or DMC and it showed higher antitumor, antipromoter, and anticarcinogenic activities ${ }^{23,24}$. The molecule exists as keto-enol tautomers shown in Figure 1. However, BDMC, as curcumin and DMC, has low aqueous solubility and poor bioavailability that hindered its pharmaceutical usage (issue 2$)^{25}$. Few studies have been carried out on BDMC, especially on its solid state forms. Karlsen etc. ${ }^{26}$ reported the formation of a BDMC monohydrate. A solvate crystallized from methanol was found by Tønnesen ${ }^{27} . \mathrm{Kasai}^{28}$ reported $^{2}$ the isopropanol solvate and confirmed the formation of a methanol solvate. Solvates crystallized from ethyl acetate and acetonitrile were also described in a patent ${ }^{29}$.

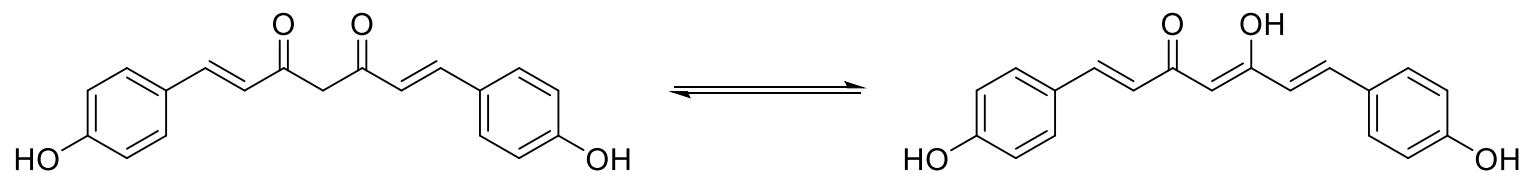

Figure 1. Molecular structure of BDMC (keto and enol tautomers).

Therefore, initiated by the idea of using the property of solvate formation to address issue 1 and to resolve issue 2 by obtaining new polymorphs of BDMC through the desolvation process, the current work focuses on the fundamental investigation of BDMC and its solvates by assessing their structures and stabilities. The crystal structures of BDMC and its solvates were determined by single crystal X-ray diffraction. The solvates were thoroughly characterized by various analytical techniques, namely, powder X-ray diffraction (PXRD), thermal analyses (TGA/DSC), temperature-resolved powder X-ray diffraction (TR-PXRD), hot-stage microscopy (HSM) and dynamic vapor sorption (DVS). Moreover, the desolvation mechanism was investigated. 


\section{EXPERIMENTAL SECTION}

2.1. Materials. Bis(demethoxy)curcumin (BDMC) (CAS No. 24939-16-0), purity higher than 98\%, was obtained from TCI (Tokyo, Japan). The used solvents (ethanol, acetone, methanol and isopropanol) of HPLC grade were purchased from commercial suppliers and used as received.

2.2. Preparation of Powdered Solvates. Saturated solutions were prepared in $5 \mathrm{~mL}$ glass vials by dissolving BDMC in the solvents at temperatures close to the boiling point of their respective solvents. The saturated solutions were then filtered while hot using $0.45 \mu \mathrm{m}$ membrane filters (Millipore). Then solutions were cooled down to room temperature until the solid solvates crystallized. In the case of no appearance of solids, the solutions were kept at $-20{ }^{\circ} \mathrm{C}$ in the refrigerator to induce the crystallization.

2.3. Preparation of Single Crystals of BDMC Solvates. Single crystals of BDMC solvates suitable for X-ray diffraction were prepared as follows: BDMC was suspended in the respective solvents (ethanol, acetone, methanol and isopropanol) at room temperature and stirred for 2 hours to reach the saturation. The suspensions were filtered through $0.45 \mu \mathrm{m}$ membrane filters (Millipore) and slowly evaporated at ambient conditions with caps perforated by a needle.

2.4. Crystal Structure Determinations. Single crystal X-ray diffraction (SCXRD) was measured on a Stoe IPDS $2 \mathrm{~T}$ diffractometer using Mo-Ka radiation ( $0.71073 \AA$ ) from a classical sealed X-ray tube equipped with a graphite monochromator. Measurements were carried out at a temperature of $100 \mathrm{~K}$. Temperature was achieved by using an Oxford Cryosystems Cryostream 700 open flow cooling device. The data was processed with the manufacturer provided X-AREA software package. Structures were solved using dual space-algorithms as implemented in SHELXT $^{30}$ and refined using SHELXL ${ }^{31}$. 
2.5. Crystal Structure Analyses. Illustrations of the crystal structure were analyzed in Diamond (V.3.2).

Intermolecular Analyses. Crystal Explorer (V.3.1) ${ }^{32}$ was used to interpret the intermolecular interactions by analyzing the two-dimensional fingerprint plots of the Hirshfeld surface. The surface is constructed by partitioning the space of crystals into regions where the electron density from the sum of spherical atoms dominates over the sum of the electron density of the crystal. For each point on the Hirshfeld surface, two distances: $d_{e}$, the distance from the point to the nearest nucleus external to the surface; and $d_{i}$, the distance to the nearest nucleus internal to the surface are defined. The different colors on the fingerprint plot represent the frequency of occurrence of the interactions, increasing from blue to green to red.

Void Map Calculations. The atom information of the solvents was deleted from the CIF and used to calculate the void maps of the solvates by Mercury (V.3.10.1). The conditions were set as follows: probe radius $0.8 \AA$, approx. grid spacing $0.7 \AA$, calculate using the contact surface.

Intermolecular Energy Calculations. The calculation of intermolecular energies (van der Waals and electrostatic) within the crystal lattice were performed using the Forcite module and COMPASS force field in Materials Studio.

Packing Coefficient Calculations. Packing coefficients were calculated by the following equation: $C_{k}=Z \cdot V_{m o l} \cdot V_{c e l l}^{-1}$, where $\mathrm{Z}$ is the number of molecules in the unit cell, $V_{m o l}$ is the molecular volume, and $V_{\text {cell }}$ is the volume of the unit cell.

2.6. Powder X-ray Diffraction (PXRD). X-ray powder data were collected on an X'Pert Pro diffractometer (PANalytical GmbH, Germany) using $\mathrm{Cu}-\mathrm{K} \alpha$ radiation $(\lambda=1.5418 \AA$ ). Samples 
were scanned in a $2 \theta$ range of $3^{\circ}$ to $40^{\circ}$ with a step size of $0.0017^{\circ}$ and a counting time of $50 \mathrm{~s}$ per step. Samples were measured at ambient temperature directly after taking out of mother liquors.

Temperature-Resolved Powder X-Ray Diffraction (TR-PXRD). To apply a linear increase of temperature and compare the TR-PXRD results with other techniques, such as DSC and HSM, freshly prepared samples were heated to the desired temperatures at $5{ }^{\circ} \mathrm{C} \cdot \mathrm{min}^{-1}$ on a separated Linkam THMS 600 heating plate and measured with PXRD at ambient temperature.

Time-Resolved Powder X-Ray Diffraction. Solid samples were measured by PXRD immediately after taking out of the mother liquor. The same conditions were used as the measuring conditions of PXRD. An automated program was set with continuous cycles of measurements.

2.7. Thermal Analyses. Thermogravimetric/differential scanning calorimetry (TGA/DSC) analyses were performed on a Netzsch STA 449 C instrument. Samples were put in a $25 \mu \mathrm{L}$ aluminum crucible and heated at a rate of $5{ }^{\circ} \mathrm{C} \cdot \mathrm{min}^{-1}$. Helium was used as the purge gas. The chemical nature of the released gases during heating was identified by using a Netzsch QMS 403 C Mass Spectrometer (MS) coupled with the 449 C TGA/DSC apparatus.

2.8. Hot-Stage Microscopy (HSM). HSM observations were performed on a Nikon Eclipse LV100 microscope (maximum magnification 1000x) with a CCD camera and coupled with a THMS 600 hot-stage setup (Linkam), which allows an accurate control of the sample temperature $\left( \pm 1^{\circ} \mathrm{C}\right)$. Selected single crystals were loaded on a quartz cell with a cylindrical geometry $(\mathrm{d}=13 \mathrm{~mm}, \mathrm{~h}=1.3 \mathrm{~mm})$. Images were recorded in the temperature range of $30{ }^{\circ} \mathrm{C}$ and $100{ }^{\circ} \mathrm{C}$ with a heating rate of $5{ }^{\circ} \mathrm{C} \cdot \mathrm{min}^{-1}$. 
2.9. Solvent Vapor Sorption and Desorption. Solvent vapor sorption and desorption were carried out with an accurate humidity and temperature-controlled microbalance system - Dynamic Vapor Sorption (DVS-advantage, Surface Measurement System, UK). Partial pressure (PP) was controlled by continuous gas flow containing pure nitrogen and solvent vapor (acetone, methanol and isopropanol) in adequate proportions. Temperature and PP were measured with a precision of $0.1{ }^{\circ} \mathrm{C}$ and $0.5 \%$, respectively. Mass variations were recorded continuously with a precision of $0.1 \mu \mathrm{g}$. Isothermal measurements at $25{ }^{\circ} \mathrm{C}$ were constructed with ten consecutive steps of relative humidity between 0 and $90 \%$. Two programs were used depend on the solids to characterize. (i) The mass measured at a given step was considered constant when relative mass variation $\mathrm{dm} / \mathrm{dt}$ remained below $0.001 \%$ for $10 \mathrm{~min}$ and the maximum stabilization time was adjusted to 2000 min. (ii) The mass was recorded when the PP was changed every 60 min (10\% PP increment). A camera is placed directly below the sample and permits to observe the macroscopic evolution of the initial solids and serves to reinforce or guide the interpretation of the mass uptake curves ${ }^{33}$.

\section{RESULTS AND DISCUSSION}

BDMC was recrystallized from four solvents, ethanol, acetone, methanol and isopropanol. Three solvates were obtained, i.e. BDMC-acetone (BDMC-ACET), BDMC-methanol (BDMC-MeOH) and BDMC-isopropanol (BDMA-IPA). Crystals suitable for SCXRD structural determinations were obtained for pure BDMC (from ethanol) and the above mentioned three solvates.

\subsection{Crystal Structure Analyses of BDMC and Its Solvates}

Crystal structures of pure BDMC and BDMC-ACET were determined for the first time. The structures of BDMC-MeOH and BDMC-ACET were found to be consistent with the reported 
data $^{27,28}$. The crystallographic data collected are summarized in Table 1 . Thermal ellipsoid plots of the asymmetric unit of BDMC and its solvates are shown in Figure 2.

Table 1. Crystallographic data and details on structure refinement for BDMC and its solvates.

\begin{tabular}{|c|c|c|c|c|}
\hline & $\overline{\text { BDMC }}$ & BDMC-ACET & BDMC-MeOH & BDMC-IPA \\
\hline Stoichiometry & & $1: 1$ & $1: 1$ & $1: 1$ \\
\hline Empirical formula & $\mathrm{C}_{19} \mathrm{H}_{16} \mathrm{O}_{4}$ & $\mathrm{C}_{19} \mathrm{H}_{16} \mathrm{O}_{4} \cdot \mathrm{C}_{3} \mathrm{H}_{6} \mathrm{O}$ & $\mathrm{C}_{19} \mathrm{H}_{16} \mathrm{O}_{4} \cdot \mathrm{CH}_{4} \mathrm{O}$ & $\mathrm{C}_{19} \mathrm{H}_{16} \mathrm{O}_{4} \cdot \mathrm{C}_{3} \mathrm{H}_{8} \mathrm{O}$ \\
\hline Formula weight & 308.32 & 366.39 & 340.36 & 368.41 \\
\hline Temperature (K) & 100 & 100 & 100 & 100 \\
\hline Crystal system & Monoclinic & Orthorhombic & Monoclinic & Orthorhombic \\
\hline Space group & $P 2 / \mathrm{c}$ & $P$ na $2_{1}$ & $P 2_{1} / \mathrm{c}$ & $P$ na $2_{1}$ \\
\hline $\mathbf{a}(\stackrel{\AA}{\AA})$ & $17.059(7)$ & $7.479(19)$ & $6.7776(7)$ & $7.457(7)$ \\
\hline b (Å) & $7.072(3)$ & $11.340(4)$ & $7.5709(6)$ & $11.831(11)$ \\
\hline c $(\AA)$ & $24.690(10)$ & $22.506(6)$ & $32.901(4)$ & $21.864(5)$ \\
\hline$\alpha\left({ }^{\circ}\right)$ & 90 & 90 & 90 & 90 \\
\hline$\beta\left({ }^{\circ}\right)$ & $93.89(3)$ & 90 & $93.641(9)$ & 90 \\
\hline$\gamma\left({ }^{\circ}\right)$ & 90 & 90 & 90 & 90 \\
\hline $\mathrm{V}\left(\AA^{3}\right)$ & $2972.0(3)$ & $1909.0(9)$ & $1684.8(3)$ & 1929(3) \\
\hline $\mathbf{Z}$ & 8 & 4 & 4 & 4 \\
\hline$\rho_{\text {calc }}\left(\mathrm{g} \cdot \mathrm{cm}^{-3}\right)$ & 1.378 & 1.275 & 1.342 & 1.269 \\
\hline$\mu\left(\mathbf{m m}^{-1}\right)$ & 0.097 & 0.090 & 0.096 & 0.089 \\
\hline$\theta$ range of data collection $\left(^{\circ}\right)$ & $1.974-25.226$ & $1.810-29.242$ & $2.761-29.164$ & $3.229-29.196$ \\
\hline Reflections collected & 15087 & 11761 & 10199 & 13444 \\
\hline Independent reflections & 5340 & 4548 & 4385 & 4465 \\
\hline $\begin{array}{c}\text { Independent reflections } \\
\text { with } \mathrm{I}>2 \sigma \text { (l) }\end{array}$ & 4600 & 4426 & 4020 & 4366 \\
\hline Data/ parameters/restrains & $5340 / 433 / 6$ & $4548 / 255 / 4$ & $4385 / 239 / 322$ & $4465 / 259 / 5$ \\
\hline GOF (all data) & 1.205 & 1.112 & 1.162 & 1.172 \\
\hline $\begin{array}{l}\text { Final } R \text { values (all data, } \\
\qquad \mathbf{I} \geq 2 \sigma(\mathbf{l}))\end{array}$ & $0.0695,0.0575$ & $0.0559,0.0542$ & $0.0557,0.0495$ & $0.0371,0.0359$ \\
\hline $\mathrm{wR}_{2}($ all data, $\mathrm{l} \geq 2 \sigma(\mathrm{l}))$ & $0.1283,0.1238$ & $0.1418,0.1404$ & $0.1184,0.1148$ & $0.0848,0.0843$ \\
\hline
\end{tabular}




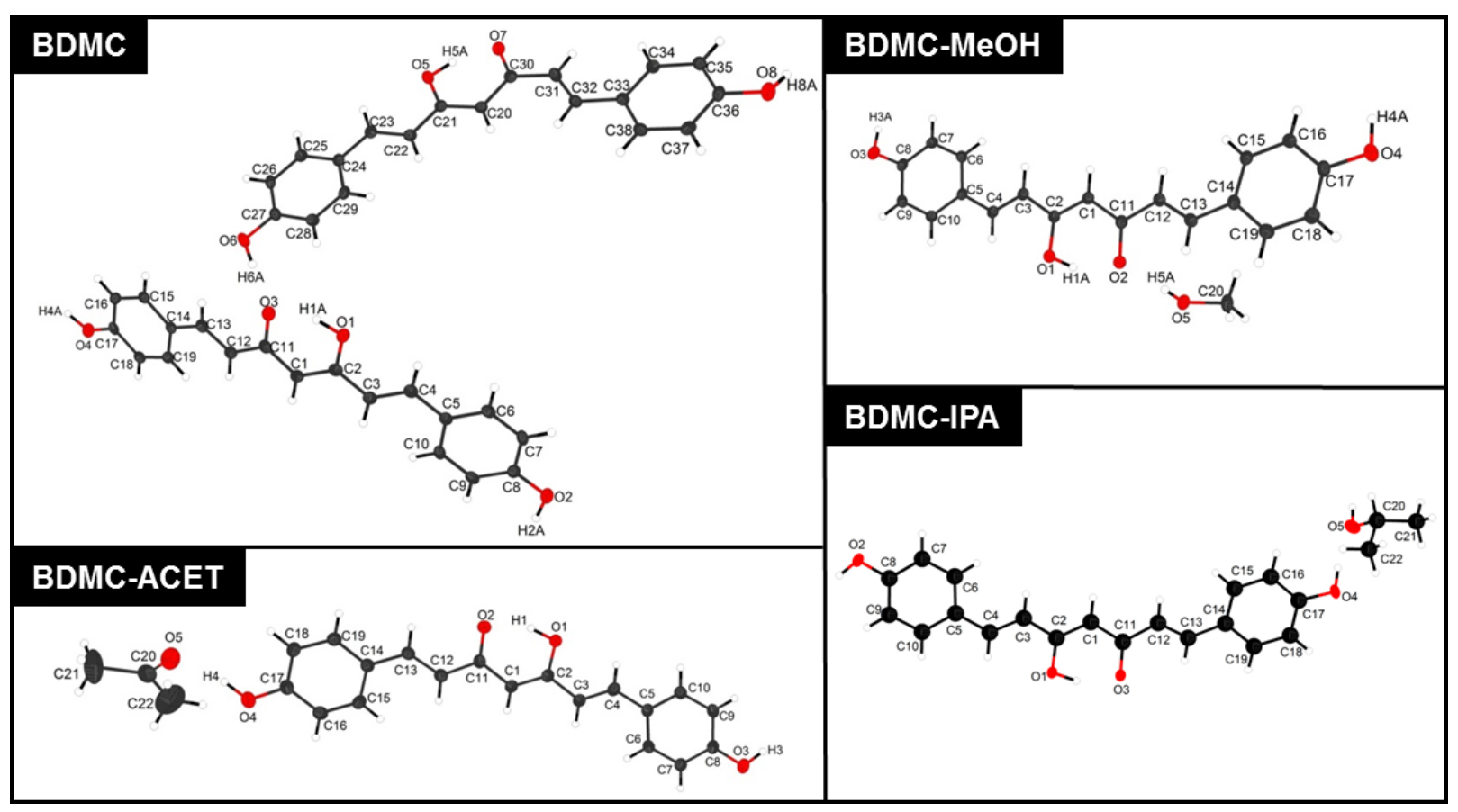

Figure 2. Asymmetric units of BDMC, BDMC-ACET, BDMC-MeOH and BDMC-IPA showing the thermal ellipsoids with 50\% probability (except the hydrogen atoms).

The crystal structure of pure BDMC, obtained from ethanol solutions, was solved and refined in the monoclinic space group $P 2 / \mathrm{c}$. The asymmetric unit is composed of two molecules of BDMC. Their superimposition emphasizes the different conformations (Figure SI-1). The two independent molecules are held together by intermolecular $\mathrm{O}_{2}-\mathrm{H}_{2 \mathrm{~A}} \ldots \mathrm{O}_{7}(1.84 \AA)$ and $\mathrm{O}_{6^{-}}$ $\mathrm{H}_{6 \mathrm{~A}} \ldots \mathrm{O}_{3}(1.78 \AA)$ hydrogen bonds. These interactions give rise to molecular chains spreading along $a$ axis (Figure 3 (a)). A second pair of hydrogen bonds, $\mathrm{O}_{8}-\mathrm{H}_{8 \mathrm{~A}} \ldots \mathrm{O}_{5}(2.06 \AA)$ and $\mathrm{O}_{4^{-}}$ $\mathrm{H}_{4 \mathrm{~A}} \ldots \mathrm{O}_{1}(2.12 \AA)$, ensures the cohesion between adjacent molecular chains (Figure 3 (b)). Therefore, a three-dimensional network is formed and the packings are shown in Figure SI-2. Relevant distances and angles of hydrogen bonds are listed in Table 2 along with the graph set notations $^{2}$. 
Hirshfeld surface analysis is a useful tool to evaluate the most dominant intermolecular interactions in crystals ${ }^{34,35}$. Close contacts in the molecular crystals are represented in red in the Hirshfeld surface plot (Figure 4) and represented as spikes circled by red and green in the fingerprint plot. The combined $\mathrm{O} \ldots \mathrm{H}$ interactions are responsible for the close contacts in the molecular packing.

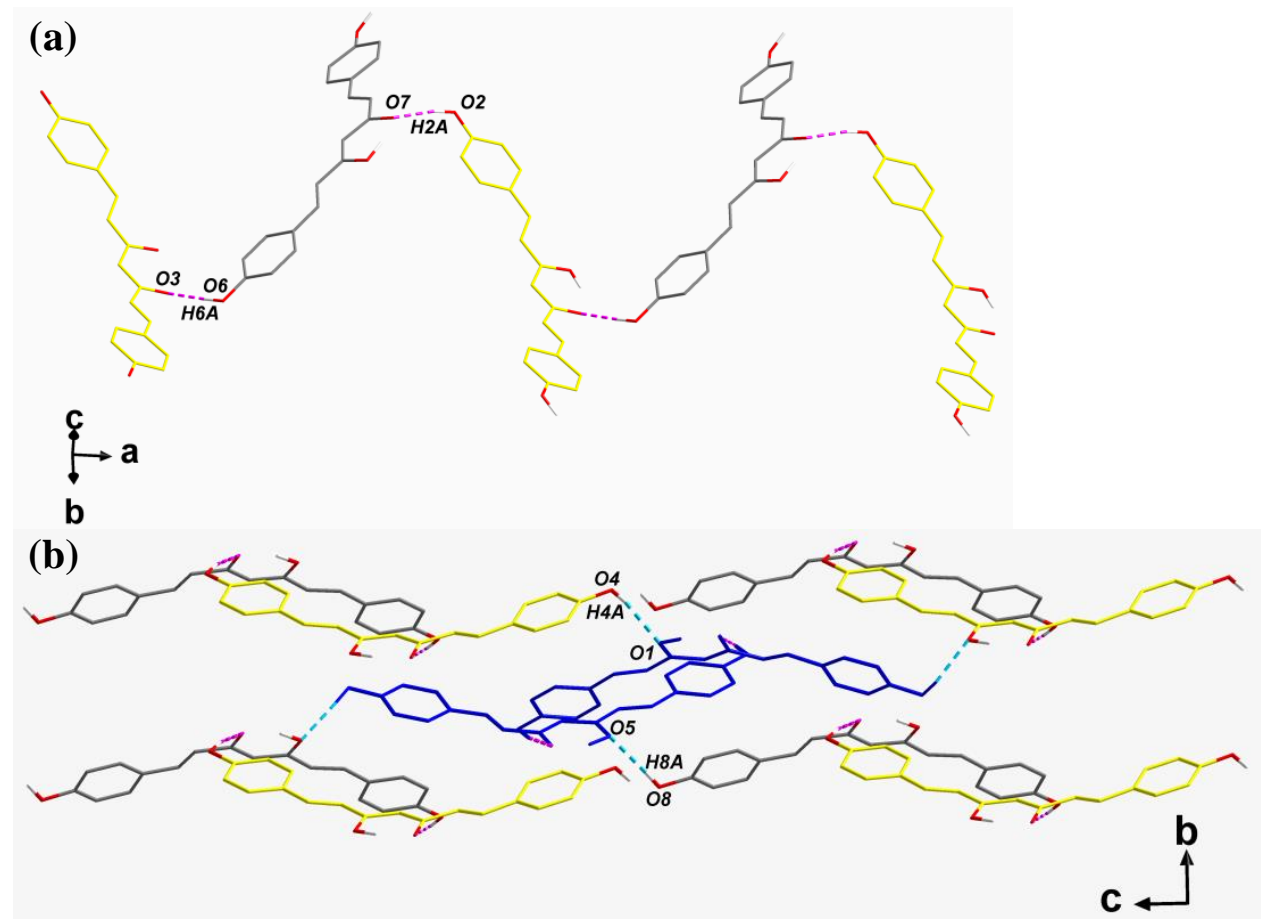

Figure 3. Molecular packings of BDMC. (a) First pair of hydrogen bonds (dashed pink lines) with $\mathrm{d}<2$ A shows the molecular chains spreading along $a$ axis, and (b) second pair of hydrogen bonds (dashed blue lines) with $\mathrm{d}>2 \AA$, ensures the cohesion with adjacent molecular bond chains (the molecular chain in (a) is displayed in blue). 
Table 2. Distances and angles of hydrogen bonds in the crystal structure of BDMC, BDMCACET, BDMC-MeOH and BDMC-IPA.

\begin{tabular}{|c|cccccc|}
\hline Solvate & $\begin{array}{c}\text { Donor } \\
\text { atom }\end{array}$ & $\begin{array}{c}\text { Hydrogen } \\
\text { atom }\end{array}$ & $\begin{array}{c}\text { Acceptor } \\
\text { atom }\end{array}$ & $\mathbf{d}(\mathbf{H} . . \mathbf{A}) / \mathbf{A}$ & Angle DHA/ $^{\circ}$ & $\begin{array}{c}\text { Graph set } \\
\text { notations }\end{array}$ \\
\hline & $\mathrm{O}_{1}$ & $\mathrm{H}_{1 \mathrm{~A}}$ & $\mathrm{O}_{3}$ & $1.60(2)$ & $155(2)$ & $S_{1}^{1}(6)$ \\
& $\mathrm{O}_{2}$ & $\mathrm{H}_{2 \mathrm{~A}}$ & $\mathrm{O}_{7}$ & $1.84(2)$ & $169(2)$ & $D_{1}^{1}(2)$ \\
BDMC & $\mathrm{O}_{4}$ & $\mathrm{H}_{4 \mathrm{~A}}$ & $\mathrm{O}_{1}$ & $2.12(3)$ & $141(2)$ & $C_{1}^{1}(12)$ \\
& $\mathrm{O}_{5}$ & $\mathrm{H}_{5 \mathrm{~A}}$ & $\mathrm{O}_{7}$ & $1.58(2)$ & $154(2)$ & $S_{1}^{1}(6)$ \\
& $\mathrm{O}_{6}$ & $\mathrm{H}_{6 \mathrm{~A}}$ & $\mathrm{O}_{3}$ & $1.78(3)$ & $172(2)$ & $D_{1}^{1}(2)$ \\
& $\mathrm{O}_{8}$ & $\mathrm{H}_{8 \mathrm{~A}}$ & $\mathrm{O}_{5}$ & $2.06(3)$ & $153(2)$ & $C_{1}^{1}(12)$ \\
\hline & $\mathrm{O}_{1}$ & $\mathrm{H}_{1}$ & $\mathrm{O}_{2}$ & $1.62(3)$ & $155(3)$ & $S_{1}^{1}(6)$ \\
BDMC- & $\mathrm{O}_{3}$ & $\mathrm{H}_{3}$ & $\mathrm{O}_{2}$ & $1.83(4)$ & $162(3)$ & $C_{1}^{1}(12)$ \\
ACET & $\mathrm{O}_{4}$ & $\mathrm{H}_{4}$ & $\mathrm{O}_{5}$ & $1.80(3)$ & $166(3)$ & $D_{1}^{1}(2)$ \\
\hline & $\mathrm{O}_{1}$ & $\mathrm{H}_{1 \mathrm{~A}}$ & $\mathrm{O}_{2}$ & $1.62(1)$ & $152(1)$ & $S_{1}^{1}(6)$ \\
BDMC- & $\mathrm{O}_{3}$ & $\mathrm{H}_{3 \mathrm{~A}}$ & $\mathrm{O}_{5}$ & $1.76(2)$ & $169(2)$ & $D_{1}^{1}(2)$ \\
MeOH & $\mathrm{O}_{4}$ & $\mathrm{H}_{4 \mathrm{~A}}$ & $\mathrm{O}_{5}$ & $1.82(2)$ & $166(2)$ & $D_{1}^{1}(2)$ \\
& $\mathrm{O}_{5}$ & $\mathrm{H}_{5 \mathrm{~A}}$ & $\mathrm{O}_{2}$ & $1.79(2)$ & $162(2)$ & $D_{1}^{1}(2)$ \\
\hline \multirow{3}{*}{ BDMC- } & $\mathrm{O}_{1}$ & $\mathrm{H}_{1 \mathrm{~A}}$ & $\mathrm{O}_{3}$ & $1.62(2)$ & $152(2)$ & $S_{1}^{1}(6)$ \\
IPA & $\mathrm{O}_{2}$ & $\mathrm{H}_{2}$ & $\mathrm{O}_{3}$ & $1.82(2)$ & $163(2)$ & $C_{1}^{1}(12)$ \\
& $\mathrm{O}_{4}$ & $\mathrm{H}_{4 \mathrm{~A}}$ & $\mathrm{O}_{5}$ & $1.72(2)$ & $168(2)$ & $D_{1}^{1}(2)$ \\
& $\mathrm{O}_{5}$ & $\mathrm{H}_{5}$ & $\mathrm{O}_{4}$ & $1.89(2)$ & $157(2)$ & $D_{1}^{1}(2)$ \\
\hline
\end{tabular}

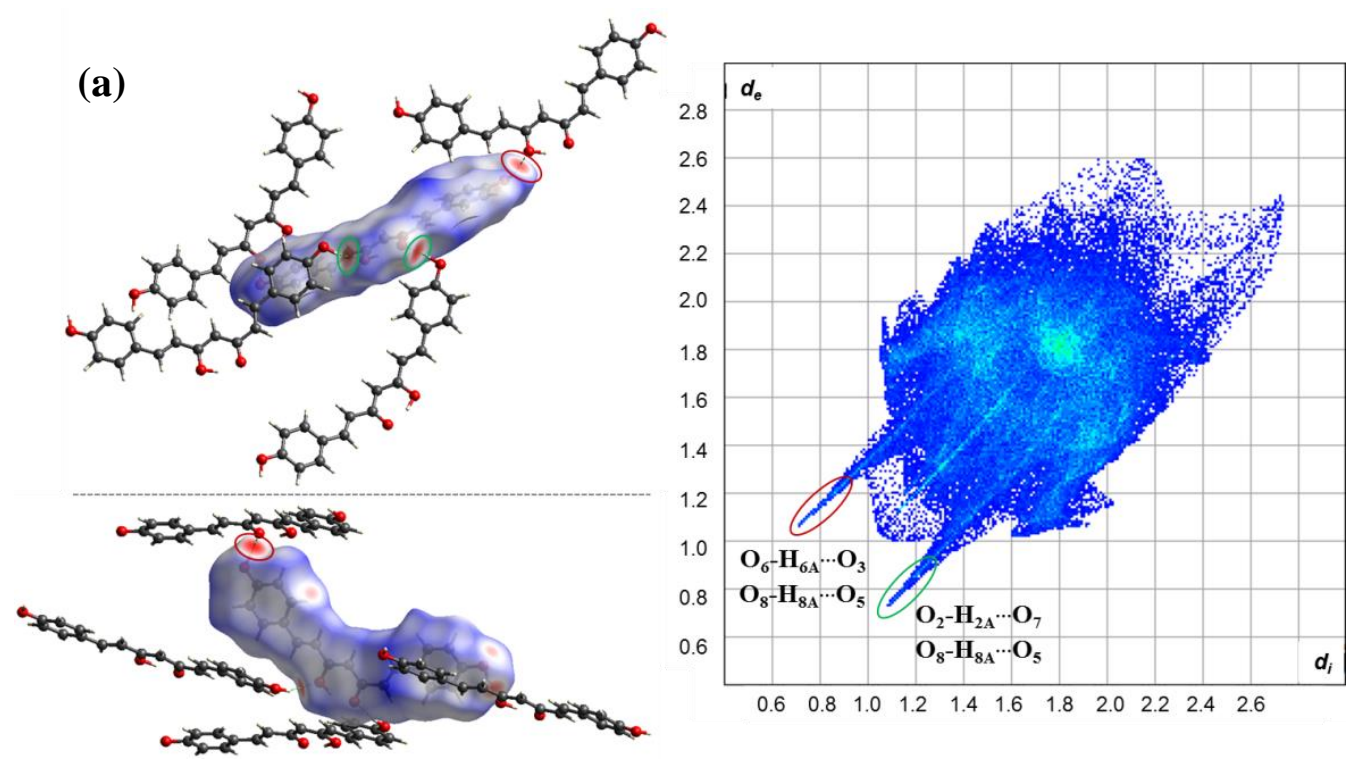



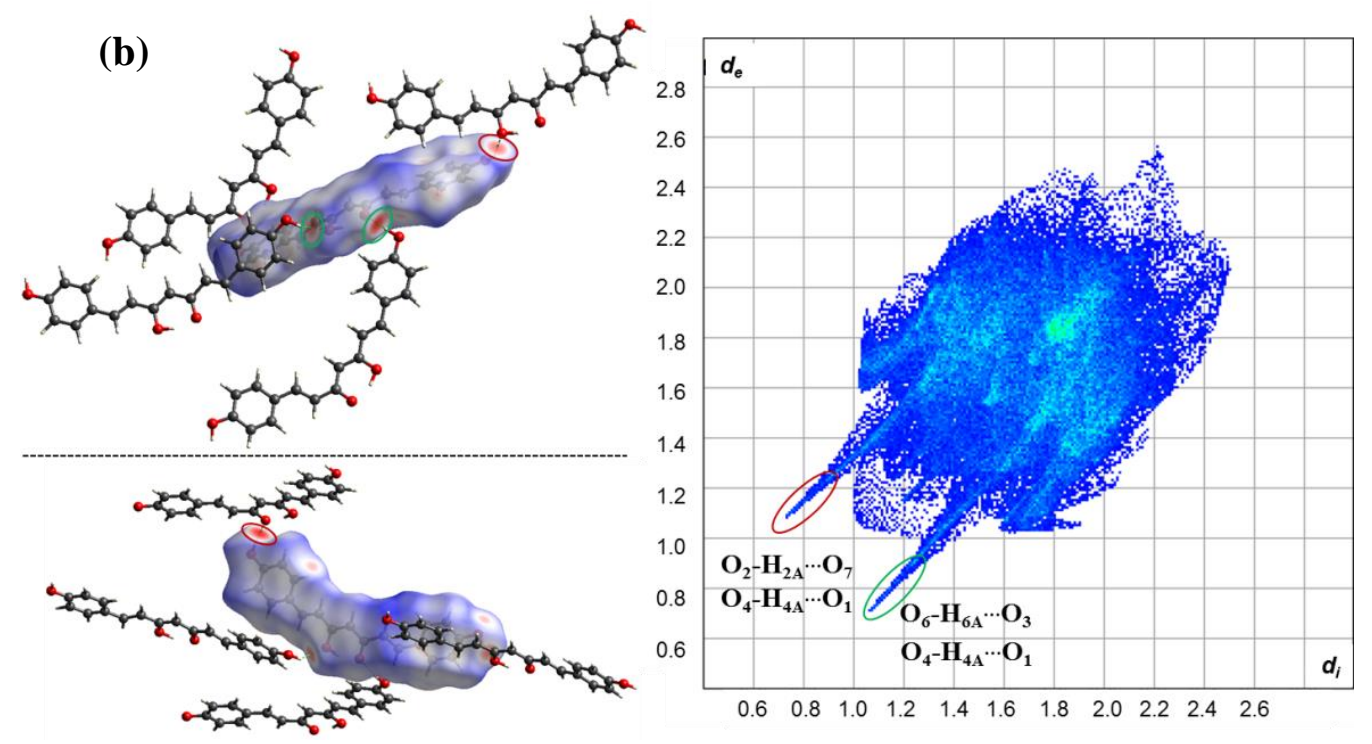

Figure 4. (a) Hirshfeld surface of one of the BDMC molecules in the asymmetric unit (shown in grey in Figure 3) showing the environment of the molecules and the corresponding fingerprint plot, and (b) Hirshfeld surface of the other BDMC molecule in the asymmetric unit (shown in yellow in Figure 3) and its fingerprint plot.

BDMC-ACET crystallizes in the orthorhombic space group $P$ na $2_{1}$. The asymmetric unit is composed of one molecule of BDMC and one solvent molecule. Acetone molecules are connected to the BDMC molecules by $\mathrm{O}_{4}-\mathrm{H}_{4} \ldots \mathrm{O}_{5}(1.80 \AA)$ hydrogen bonding. BDMC molecules are connected to each other by intermolecular $\mathrm{O}_{3}-\mathrm{H}_{3} \ldots \mathrm{O}_{2}(1.83 \AA)$ hydrogen bonding. The interaction leads to molecular chains spreading along $c$ axis (Figure 5 (a)). A network of BDMC is formed by this interval connection of BDMC molecules. The molecular packings of BDMCACET are shown in Figure 5 (b) and Figure SI-3. The close contacts in BDMC-ACET can be seen from the Hirshfeld surface analysis (Figure SI-4 (a)) and the corresponding fingerprint plot (Figure SI-4 (b)). 

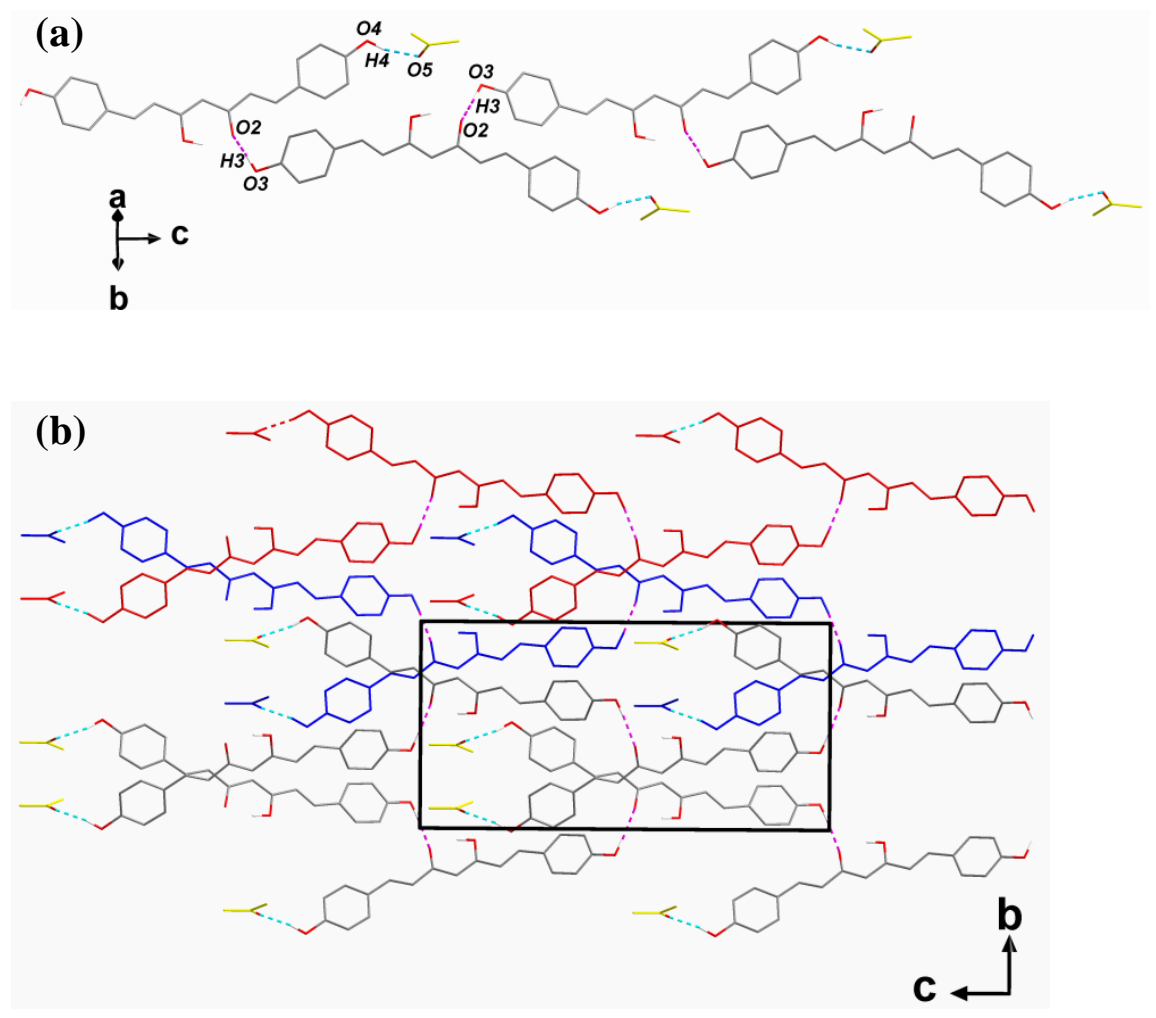

Figure 5. (a) Molecular chains of BDMC-ACET generated via hydrogen bonds $\mathrm{O}_{4}-\mathrm{H}_{4} \ldots \mathrm{O}_{5}$ and $\mathrm{O}_{3}-\mathrm{H}_{3} \ldots \mathrm{O}_{2}$, and (b) Projection of the BDMC-ACET packing along $a$ axis. Standard molecular bond chains are displayed in yellow and grey. Some are displayed in red and blue to show clearly the propagation and orientation of the molecular chains.

BDMC-MeOH crystallizes in the monoclinic space group $P 2{ }_{1} / \mathrm{c}$. The asymmetric unit is composed of one molecule of BDMC and one molecule of solvent. There is no direct hydrogen bond between adjacent BDMC molecules. They are connected by the methanol molecules via hydrogen bonds $\mathrm{O}_{3}-\mathrm{H}_{3 \mathrm{~A}} \ldots \mathrm{O}_{5}(1.76 \AA)$ and $\mathrm{O}_{5}-\mathrm{H}_{5 \mathrm{~A}} \ldots \mathrm{O}_{2}(1.79 \AA)$. The solvent molecule acts as a bridge between consecutive molecular chains through $\mathrm{O}_{4}-\mathrm{H}_{4 \mathrm{~A}} \ldots \mathrm{O}_{5}(1.82 \AA)$ hydrogen bonding (Figure 6). This latter hydrogen bonding interaction generates molecular layers spreading in $a b$ with a thickness of $\mathrm{d}_{002}$ by connecting the molecular chains. These molecular layers stack along $c$ and the cohesion is ensured by van der Waals interactions (Figure 7). The Hirshfeld surface 
(Figure SI-5 (a)) shows the close contacts of BDMC molecules in the BDMC-MeOH (red spots) and marked as spikes by circles in the fingerprint plot (Figure SI-5 (b)).

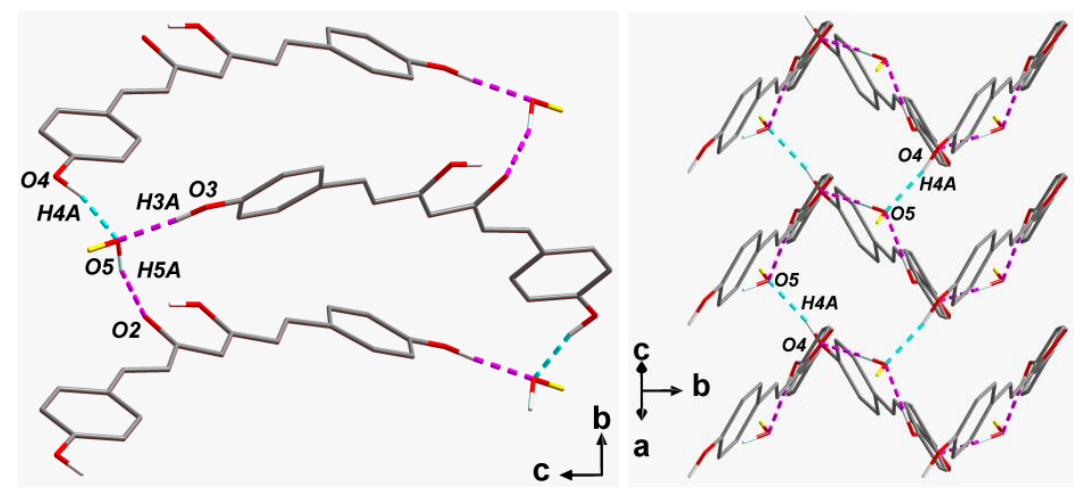

Figure 6. Projection of hydrogen bonding connections in BDMC-MeOH along different directions.

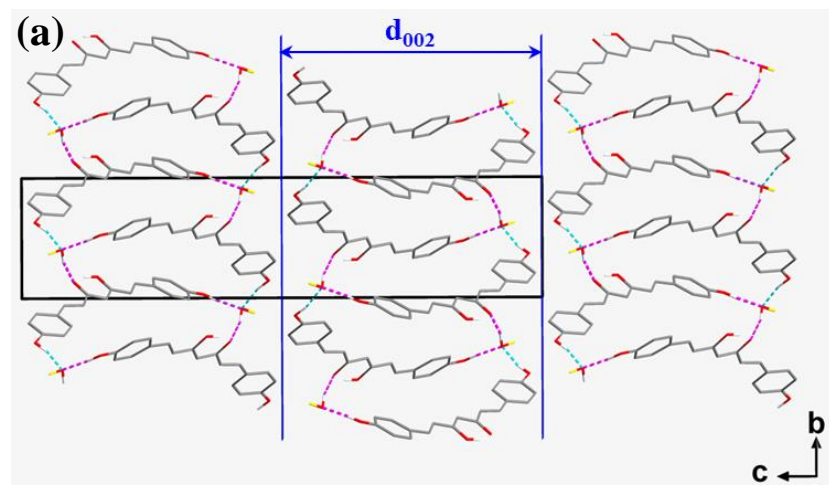

(b)

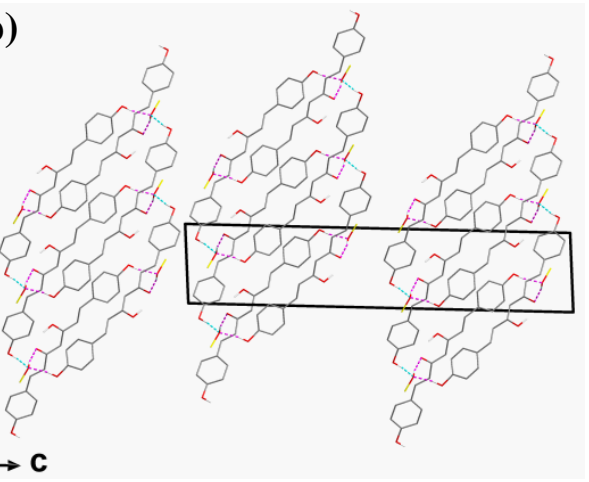

Figure 7. (a) Projection of BDMC-MeOH layers along $a$ spreading in $a b$ and stacking along $c$, which exhibits a thickness of $\mathrm{d}_{002}$, and (b) projection of BDMC-MeOH layers along $b$.

BDMC-IPA crystallizes in the orthorhombic space group Pna2 $2_{1}$. The asymmetric unit is composed of one molecule of BDMC and one molecule of solvent. BDMC molecules are connected to each other by intermolecular $\mathrm{O}_{2}-\mathrm{H}_{2} \ldots \mathrm{O}_{3}(1.82 \AA)$ hydrogen bonding, which leads to the molecular chains spreading in [011] direction (Figure SI-6). Solvent molecules are connected 
to BDMC molecular chains by $\mathrm{O}_{4}-\mathrm{H}_{4} \ldots \mathrm{O}_{5}(1.72 \AA)$ hydrogen bonding (Figure 8 (a)). The isopropanol molecules establish a second type of hydrogen bonding by means of the hydroxyl moiety $\mathrm{O}_{5}-\mathrm{H}_{5} \ldots \mathrm{O}_{4}(1.89 \AA)$ along $a$ axis (Figure 8 (b)). This latter interaction generates a threedimensional network of hydrogen bonding that ensures the cohesion of the structure (Figure 8 (c) and Figure SI-7). The close contacts in BDMC-IPA can be seen from the Hirshfeld surface (Figure SI-8 (a)) and the corresponding fingerprint plot (Figure SI-8 (b)).

(a)
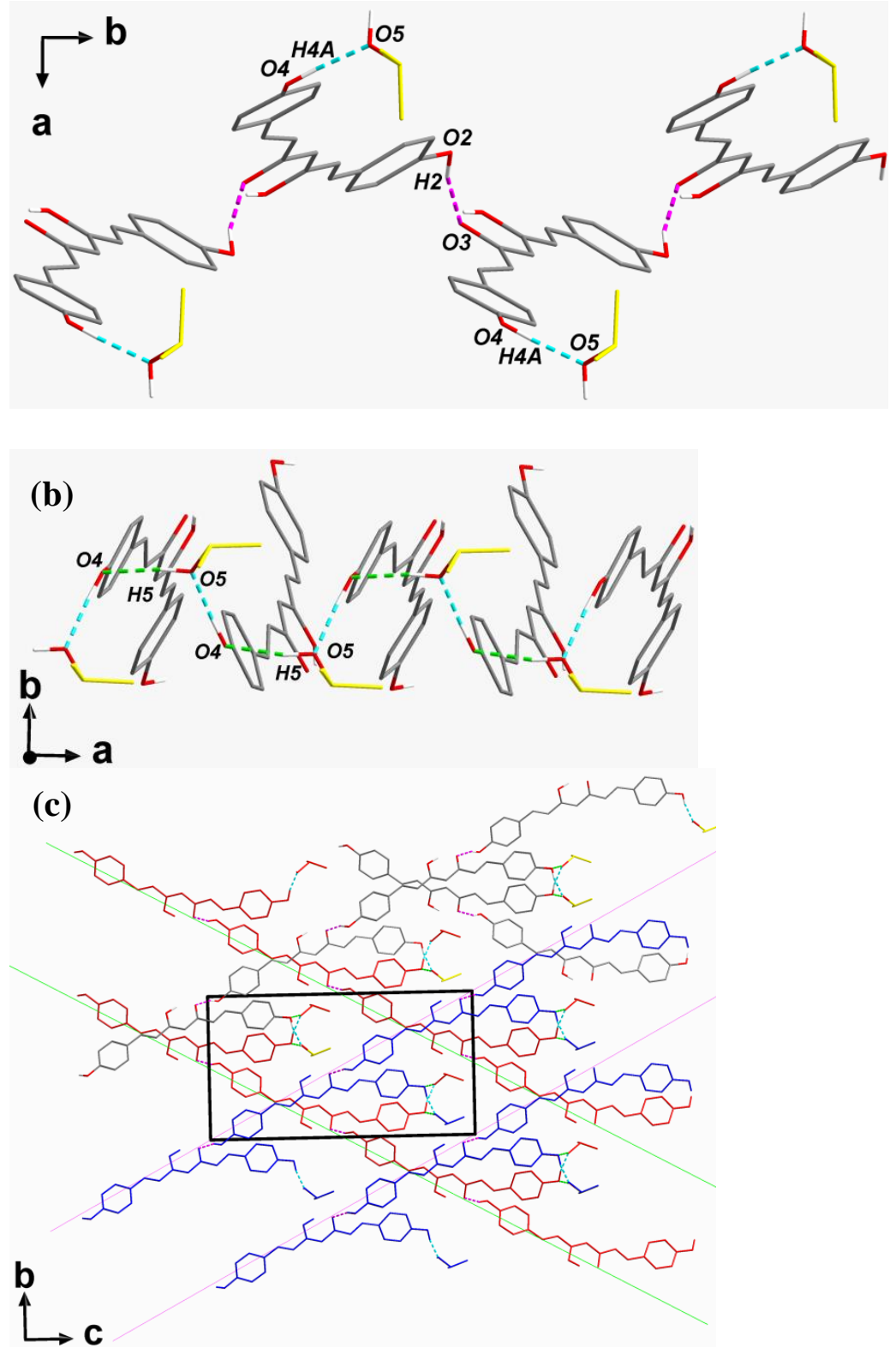
Figure 8. (a) Molecular chains of BDMC-IPA formed by hydrogen bonding of BMDC molecules $\left(\mathrm{O}_{2}-\mathrm{H}_{2} \ldots \mathrm{O}_{3}\right.$, dashed pink lines). Isopropanol molecules are connected to molecular chains by a first type of hydrogen bonding $\left(\mathrm{O}_{4}-\mathrm{H}_{4 \mathrm{~A}} \ldots \mathrm{O}_{5}\right.$, dashed blue lines), and (b) isopropanol molecules are connected to molecular chains by a second type of hydrogen bonding $\left(\mathrm{O}_{5}-\mathrm{H}_{5} \ldots \mathrm{O}_{4}\right.$, dashed green lines), and (c) projection of the BDMC-IPA packing along $a$. Standard molecular bond chains are displayed in yellow and grey. Some are displayed in red and blue to show clearly the propagation and orientation of the molecular chains.

\subsection{Structure Comparisons and Packing Efficiencies of BDMC and Its Solvates}

Superimposition of the BDMC molecules in the asymmetric unit of BDMC, BDMC-ACET, BDMC-MeOH and BDMC-IPA shows that the most mobile part of BDMC is one of the phenyl rings, which adopts different positions (Figure 9). The solvent molecules are connected to one of the hydroxyl groups on the phenyl ring of BDMC molecules and are organized in a zigzag manner. In the crystal structure of BDMC-MeOH, methanol molecules are strongly involved in the formation of the hydrogen bonding network and connect all the BDMC molecules through three hydrogen bonding interactions. Therefore, the stability of BDMC-MeOH could be expected to be higher as compared to BDMC-ACET and BDMC-IPA, in which the solvent molecules are bonded to the BDMC molecules through only one (in BDMC-ACET) or two (in BDMC-IPA) hydrogen bonding interactions. Moreover, comparison of the void maps (Figure 10) indicates that the desolvation of BDMC-ACET and BDMC-IPA should be relatively facile because of the

existence of void channels in the molecular structures, which take up $25.3 \%(483.19 \AA)$ and $25.6 \%(494.48 \AA)$ of the unit cell volume in BDMC-ACET and BDMC-IPA, respectively. 
However, the void channel is absent in the crystal structure of BDMC-MeOH and the methanol solvent only takes up $8.5 \%$ (143.59 ̊̊) of the unit cell.

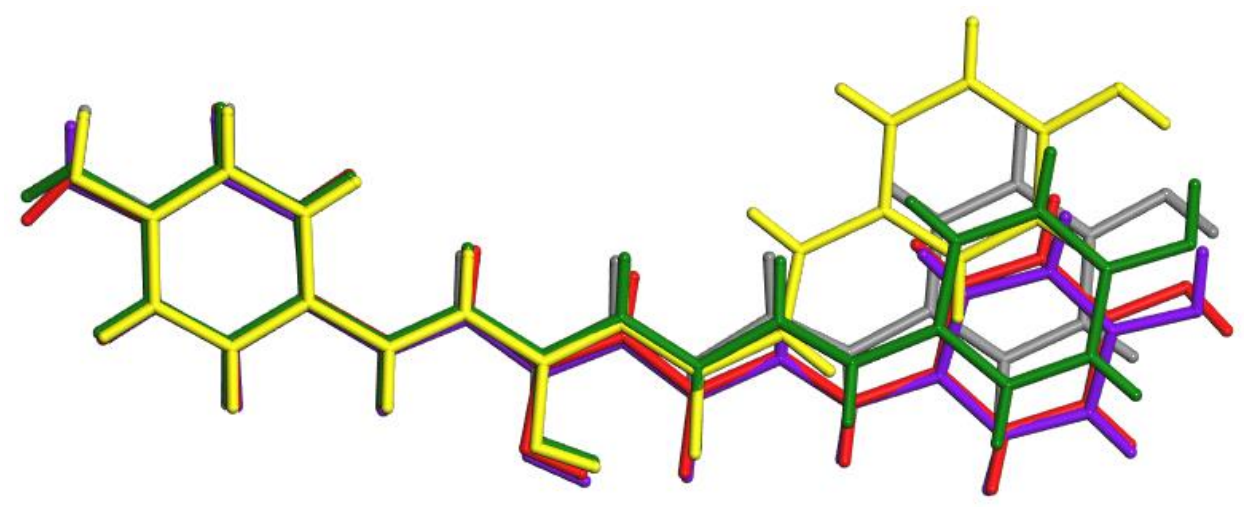

Figure 9. Superimposition of the BDMC molecules in the asymmetric units of BDMC (in yellow and grey), BDMC-ACET (in red), BDMC-MeOH (in purple) and BDMC-IPA (in green).

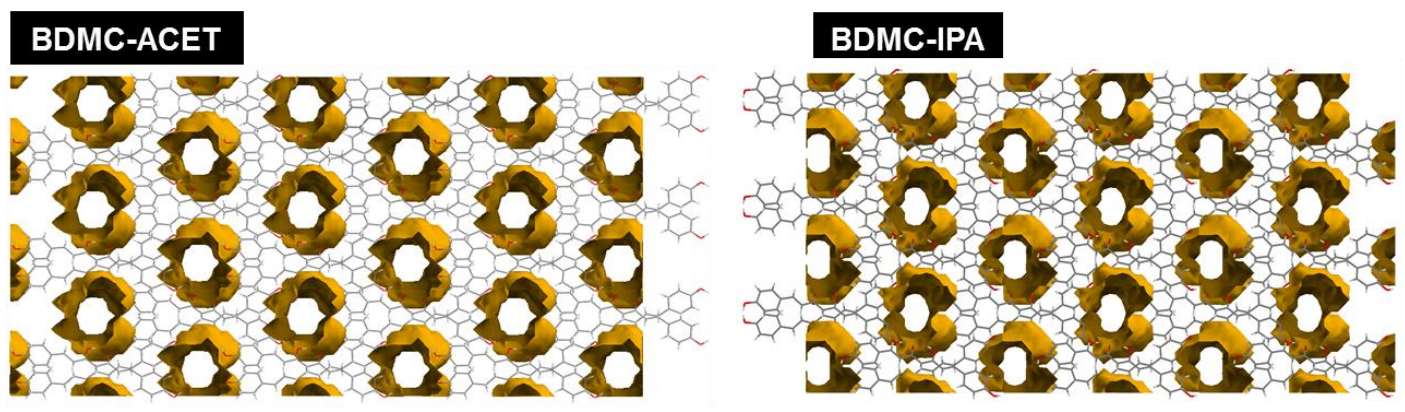

\section{BDMC-MeOH}

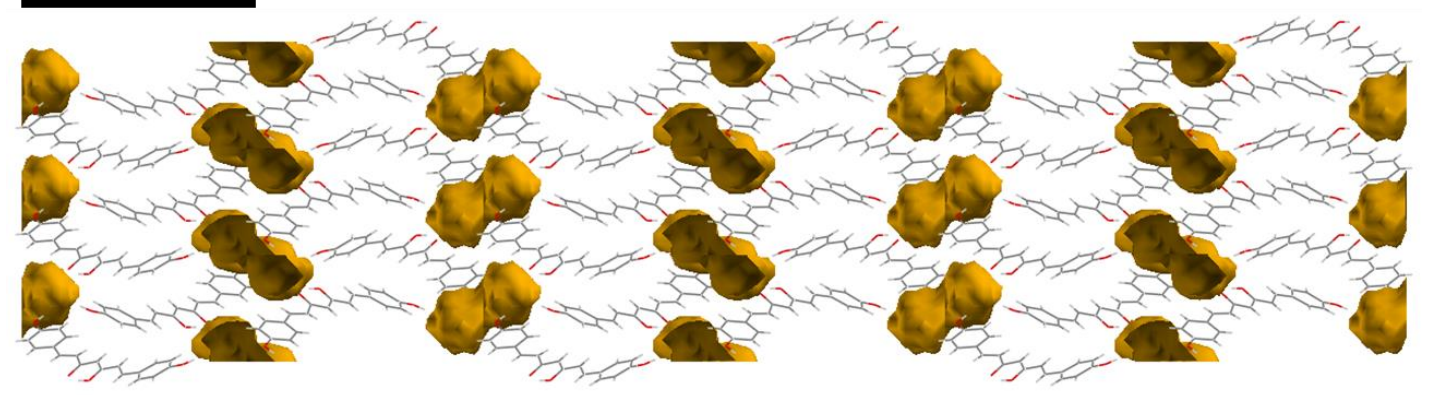

Figure 10. Void maps in the crystal structures of BDMC-ACET and BDMC-IPA as compared to BDMC-MeOH. 
According to Price et al. ${ }^{16}$, the driving force for solvate formation can be viewed as lowering the crystal free energy primarily through electrostatic and van der Waals interactions. So, the intermolecular interactions (the sum-up of van der Waals and electrostatic interactions) of BDMC and its solvates were calculated and summarized in Table 3. The results show that BDMC-MeOH and BDMC-IPA have a lower energy of intermolecular interactions compared to BDMC-ACET and pure BDMC. However, BDMC-ACET possesses a higher value than BDMC, which could be an indication of its lower stability.

Table 3. Intermolecular energies of BDMC and BDMC solvates.

\begin{tabular}{|c|c|c|c|}
\hline & 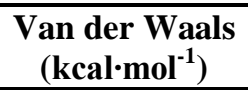 & 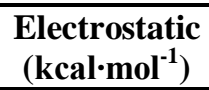 & $\begin{array}{c}\text { Intermolecular Interactions } \\
\left({\left.\mathrm{kcal} \cdot \mathrm{mol}^{-1}\right)}^{-1}\right.\end{array}$ \\
\hline BDMC & 9186 & -178 & 9008 \\
\hline BDMC-ACET & 12083 & -86 & 11997 \\
\hline ВDМС-МеОН & 4502 & -85 & 4417 \\
\hline BDMC-IPA & 4532 & -212 & 4320 \\
\hline
\end{tabular}

The packing coefficient $\left(C_{k}\right)$ is given to measure how tightly a molecule packs in a crystal lattice. It descibes the percentage of void spaces in the molecular crystals. A $C_{k}$ value of 0.6 was obtained for BDMC and its three solvates. It indicates that pure BDMC is already efficiently packed. The solvents involved are not utilized to fill the void spaces in the crystal structures, but to bind the host molecules efficiently by providing multipoint hydrogen bonding. This is probably a dominant factor that governs the inclusion of solvents in BDMC molecules.

\subsection{Stability and Desolvation of BDMC Solvates}

\subsubsection{Thermogravimetric analyses and Differential Scanning Calorimetry}

TGA/DSC analyses could give an indication of the thermal stability and the stoichiometry of the solvates by calculating the weight loss of solvents. As can be seen in Figure 11, the TGA/DSC curve of each solvate shows two separated sharp endothermic peaks that correspond to the 
desolvation process and the melting of the desolvated products, respectively. For BMDC-ACET, the desolvation started at $57^{\circ} \mathrm{C}$ (onset temperature) and ended at $62{ }^{\circ} \mathrm{C}$ (peak temperature) accompanied by a mass loss of $15.14 \%$. This is equivalent to one mole of acetone per mole of BDMC. The melting of the desolvated product (BDMC) occurred from $230{ }^{\circ} \mathrm{C}$ to $233{ }^{\circ} \mathrm{C}$ (onset and peak temperatures, respectively) and a slight mass loss was observed due to the concomitant degradation of BDMC.

All the thermal data for the three solvates are summarized in Table 4. The stoichiometry determined from TGA is consistent with the SCXRD measurements. The lowest desolvation temperature of BDMC-ACET indicates that it is less thermal stable, which is confirmed by the structural analyses. However, since desolvation is a kinetically driven process, it can be strongly affected by various factors, such as particle size distribution, relative humidity and heating rate. Still, the crystal structure is usually the dominant factor.
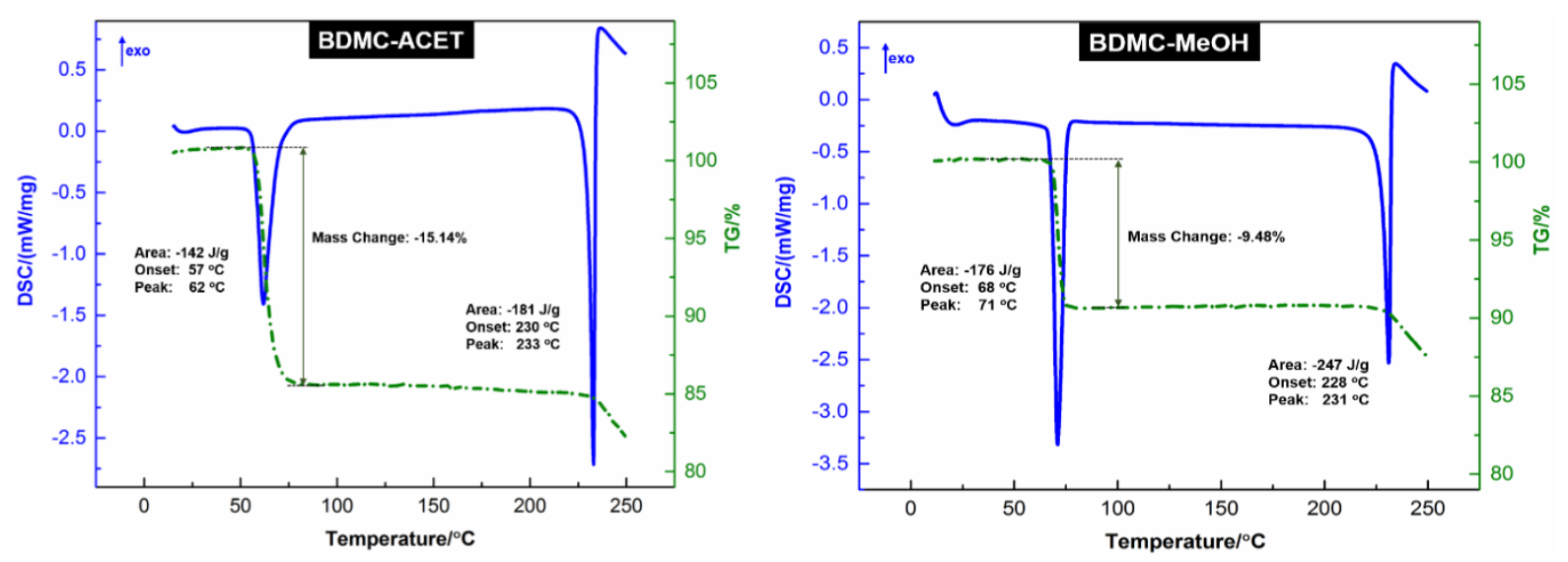


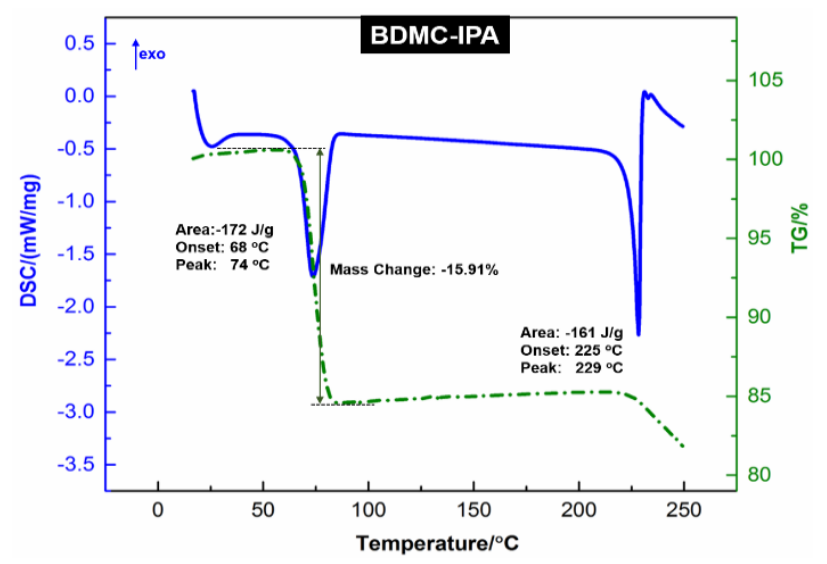

Figure 11. TGA/DSC curves show the thermal behavior with the desolvation and the melting of BDMC solvates (heating rate, $5^{\circ} \mathrm{C} \cdot \mathrm{min}^{-1}$ ).

Table 4. Thermal data and mass loss of the desolvation of BDMC solvates.

\begin{tabular}{|c|c|c|c|c|c|}
\hline \multirow[t]{2}{*}{ Solvate } & \multirow{2}{*}{$\begin{array}{c}\text { Boiling point of } \\
\text { pure solvent } \\
\left({ }^{\circ} \mathbf{C}\right)\end{array}$} & \multicolumn{2}{|c|}{$\begin{array}{c}\text { Desolvation Temperature } \\
\left({ }^{\circ} \mathrm{C}\right)(\text { DSC })\end{array}$} & \multicolumn{2}{|c|}{ Mass loss upon desolvation (\%) } \\
\hline & & $\begin{array}{c}\text { Onset T } \\
\left({ }^{\circ} \mathbf{C}\right)\end{array}$ & $\begin{array}{c}\text { Peak T } \\
\left({ }^{\circ} \mathbf{C}\right)\end{array}$ & $\begin{array}{l}\text { Calculated } \\
\text { SCXRD }\end{array}$ & Experimental TGA \\
\hline BDMC-ACET & 56 & 57 & 62 & 15.85 & 15.14 \\
\hline ВDMC-МeOH & 65 & 68 & 71 & 9.41 & 9.48 \\
\hline BDMC-IPA & 83 & 68 & 74 & 16.30 & 15.91 \\
\hline
\end{tabular}

\subsubsection{Temperature-Resolved Powder X-Ray Diffraction}

TR-PXRD patterns were collected from ambient temperature to $90^{\circ} \mathrm{C}$ at $5^{\circ} \mathrm{C} \cdot \mathrm{min}^{-1}$ to follow the desolvation process of BDMC solvates. To have a clear comparison between various temperatures, only the data in the $2 \theta$ range of $5^{\circ}$ to $35^{\circ}$ are shown here. As can be seen in Figure 12 (a), for BDMC-ACET, tiny peaks at $2 \theta=20.6^{\circ}$ and $22^{\circ}$ appeared at $50{ }^{\circ} \mathrm{C}$ (pointed out by the blue arrows). This means that desolvation of BDMC-ACET has already started. At $60{ }^{\circ} \mathrm{C}$, characteristic peaks of $\mathrm{BDMC}$ at $2 \theta=7.3^{\circ}$ and $10.2^{\circ}$ appeared. At $65^{\circ} \mathrm{C}$, peaks of BDMC at $2 \theta$ $=7.3^{\circ}, 10.2^{\circ}, 20.6^{\circ}$ and $22^{\circ}$ (blue arrows), and peaks of BDMC-ACET at $2 \theta=7.9^{\circ}, 8.7^{\circ}, 20.9^{\circ}$ and $23.6^{\circ}$ (green arrows) demonstrated the coexistence of BDMC-ACET and BDMC. The 
desolvation was not completed till $75^{\circ} \mathrm{C}$. For BDMC-MeOH (Figure 12 (b)), peaks of BDMC at $2 \theta=7.3^{\circ}, 10.2^{\circ}$ and $14.6^{\circ}$ appeared at $75^{\circ} \mathrm{C}$ and characteristic peaks of BDMC-MeOH at $2 \theta=$ $5.4^{\circ}, 10.7^{\circ}$ and $15.7^{\circ}$ disappeared at $85^{\circ} \mathrm{C}$. It indicates that the desolvation of BDMC-MeOH started at $75{ }^{\circ} \mathrm{C}$ and completed at $85^{\circ} \mathrm{C}\left(5^{\circ} \mathrm{C} \cdot \mathrm{min}^{-1}\right.$ heating rate). For BDMC-IPA (Figure $\left.12(\mathrm{c})\right)$, characteristic peaks of BDMC at $2 \theta=7.3^{\circ}, 10.2^{\circ}$ and $19.9^{\circ}$ appeared at $75^{\circ} \mathrm{C}$. At $80^{\circ} \mathrm{C}$, the coexistence of BDMC (peaks at $2 \theta=7.3^{\circ}, 10.2^{\circ}$ and $19.9^{\circ}$ ) and BDMC-IPA (peaks at $2 \theta=7.3^{\circ}$, $10.2^{\circ}$ and $19.9^{\circ}$ ) reached the maximum extent. The disappearance of the characteristic peaks of BDMC-IPA at $85^{\circ} \mathrm{C}$ indicated that the desolvation was complete. The desolvation of the three solvates showed an overlapping of the solvated and non-solvated forms. No new polymorph of BDMC was discovered after the desolvation of the three solvates.
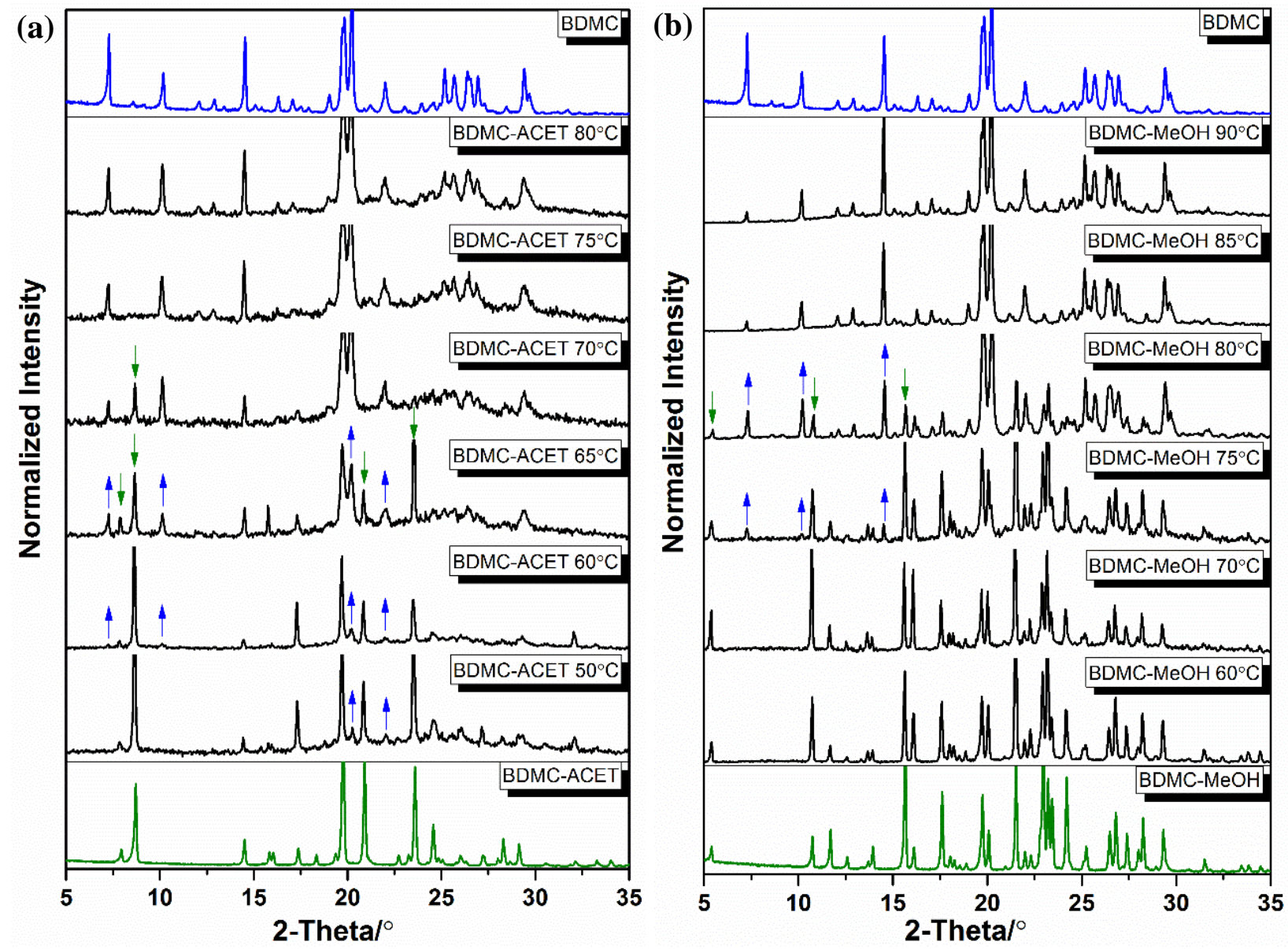


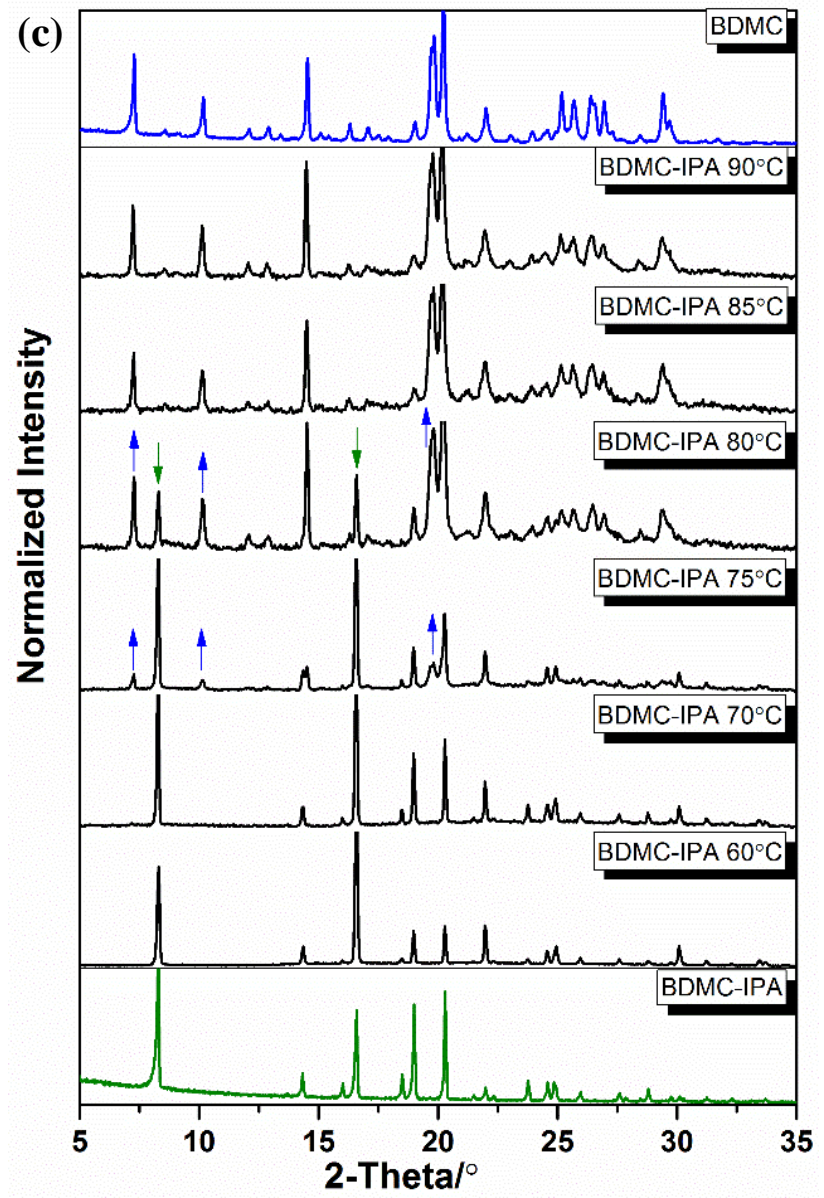

Figure 12. TR-PXRD patterns of (a) BDMC-ACET, (b) BDMC-MeOH, and (c) BDMC-IPA during the desolvation process. PXRD pattern of BDMC is shown as reference for comparison (at the top of each figure).

\subsubsection{Powder X-Ray Diffraction Analyses of the Stability of BDMC Solvates at Ambient} Conditions

In general, many solvates are known to be efflorescent and often desolvate during their storage. Stability performances of the three solvates were tested. The desolvation process of BDMCACET, BDMC-MeOH and BDMC-IPA was monitored by time-resolved PXRD at ambient conditions immediately after slight filtration on papers. As can be seen in Figure 13 (a), BDMC- 
ACET started to desolvate during the ninth cycle (after $2 \mathrm{~h}$ ) and BDMC in pure form was obtained after 50 cycles (after 13 h). BDMC-IPA (Figure 13 (b)) remained stable after 38 cycles of measurements $(10 \mathrm{~h})$ and stored overnight. Desolvation was observed after four days of storing at ambient conditions. However, no desolvation occurred for BDMC-MeOH after three months of storing at ambient conditions. Therefore, BDMC-MeOH shows the highest stability at ambient conditions compared to BDMC-ACET and BDMC-IPA.
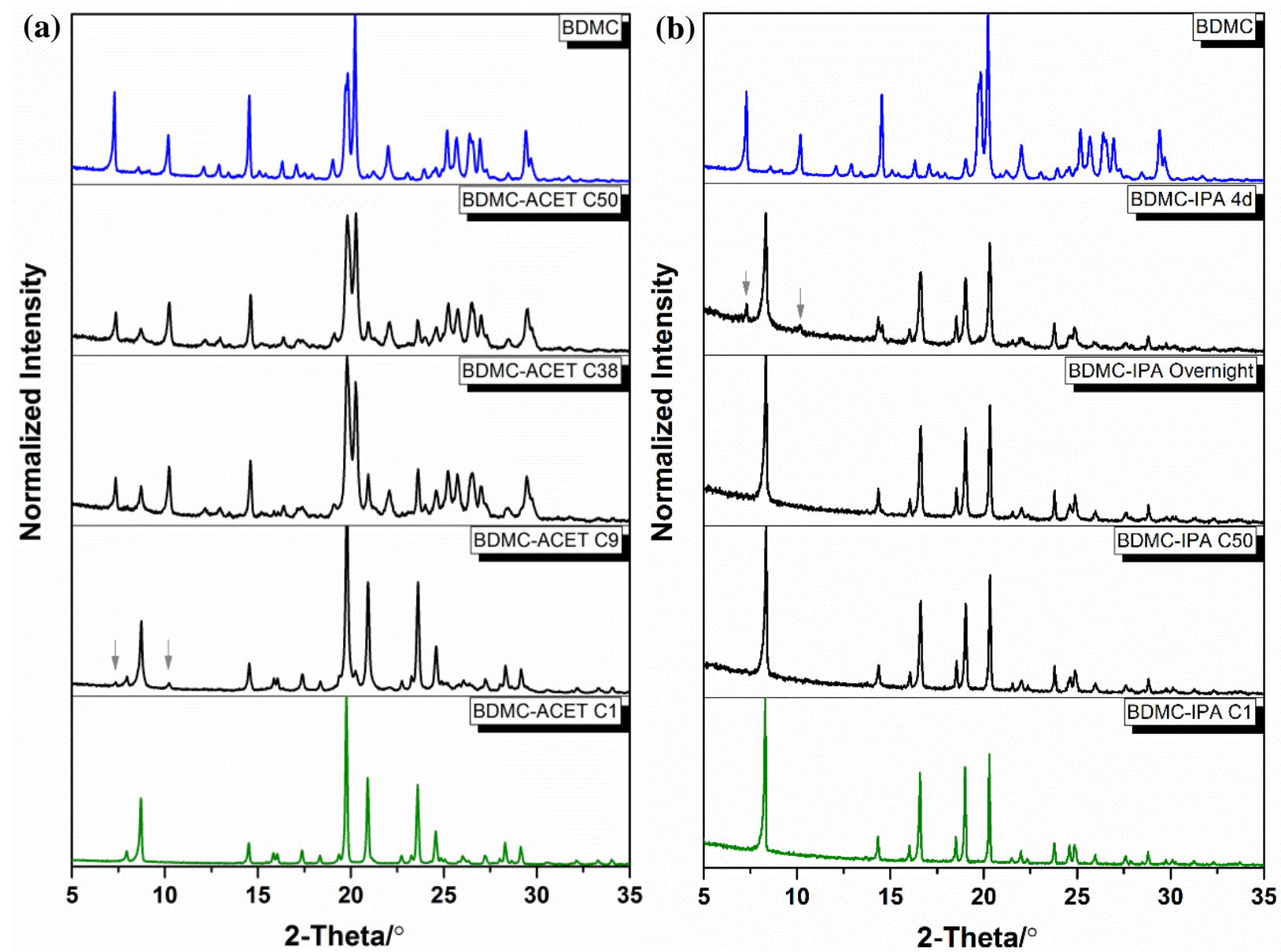

Figure 13. Time-resolved PXRD measurements of (a) BDMC-ACET, and (b) BDMC-IPA with increasing exposure time to ambient conditions. $\mathrm{C} 1, \mathrm{C} 9$ etc. denote the number of the measurement cycles. The PXRD pattern of BDMC was shown as reference for comparison (at the top of each figure). 


\subsubsection{Hot-Stage Microscopy}

In addition, visual observations of the desolvation process were performed by hot-stage microscopy (HSM). The same heating rate was applied as that used for the TR-PXRD and TGA/DSC measurements. BDMC-ACET and BDMC-IPA form thin and needle-like crystals, while BDMC-MeOH forms plate-like crystals. Upon desolvation, the classical pseudomorphosis phenomenon occurred, i.e. the original shape of the crystal is maintained but a loss of transparency could be observed ${ }^{5,36,37}$. Pictures recorded at various temperatures are presented in Figure 14. The "dark" spots indicate the appearance of BDMC, which means the occurrence of the desolvation process. For BDMC-ACET (Figure 14 (a)), traces of desolvated BDMC were observed at $60{ }^{\circ} \mathrm{C}$ under polarized light (shown as "dark" spots) and the most obvious desolvation occurred in the temperature range of $67^{\circ} \mathrm{C}$ to $69{ }^{\circ} \mathrm{C}$. At $73{ }^{\circ} \mathrm{C}$, the desolvation process was completed and accompanied by the total loss of the transparency. For BDMC$\mathrm{MeOH}$ (Figure 14 (b)), the most obvious desolvation occurred between $77^{\circ} \mathrm{C}$ and $80^{\circ} \mathrm{C}$. In Figure 14 (c), the highest rate of desolvation of BDMC-IPA occurred between $85^{\circ} \mathrm{C}$ and $87^{\circ} \mathrm{C}$. At $89^{\circ} \mathrm{C}$, the complete loss of transparency indicates the completion of the desolvation process. After desolvation, the original shapes of the three solvates were maintained, which is in accordance with the desolvation phenomenon of stoichiometric solvates.
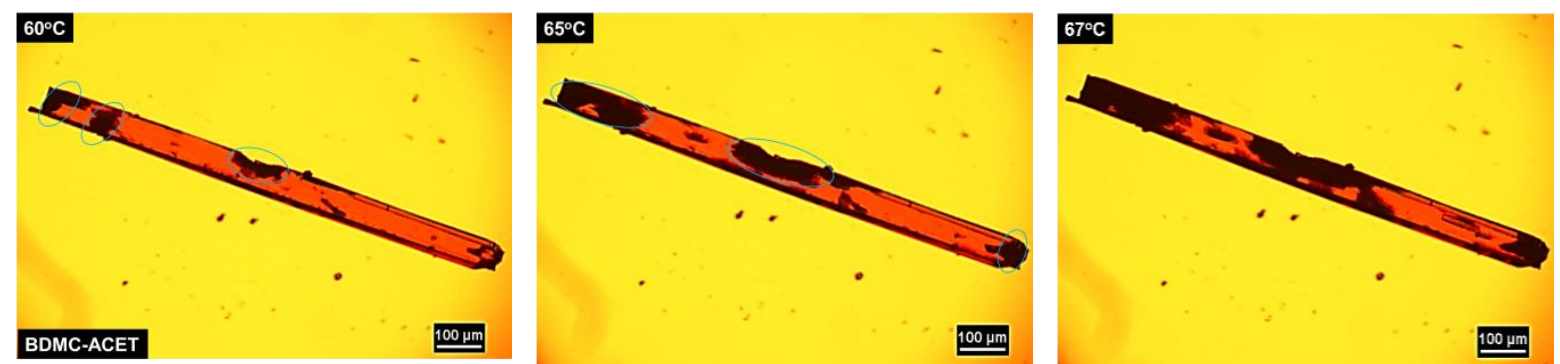

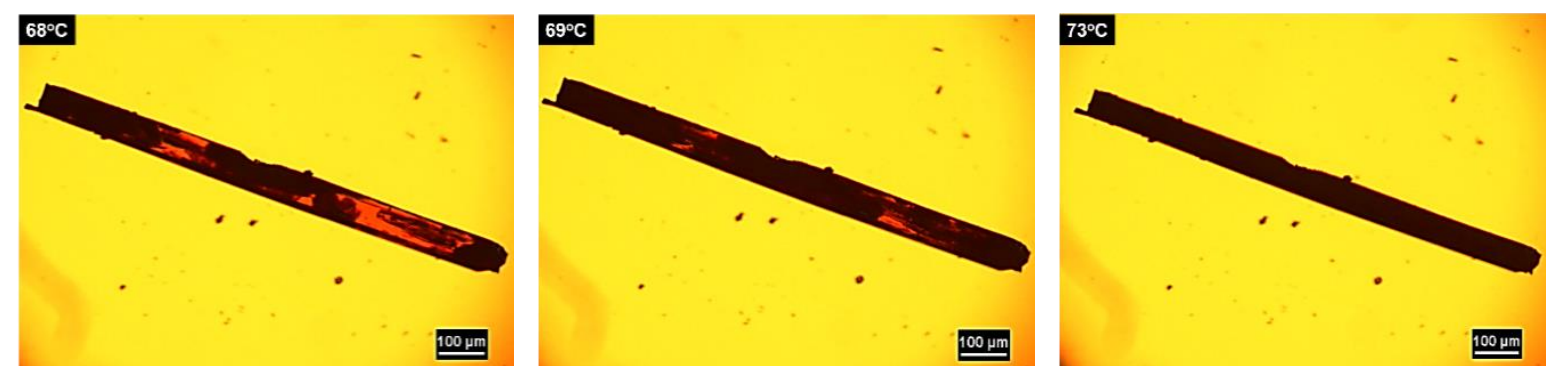

Figure 14. (a) Hot-stage microscopy (HSM) observation on the desolvation process of BDMCACET with increasing temperature at $5{ }^{\circ} \mathrm{C} \cdot \mathrm{min}^{-1}$. Several nucleation sites of the non-solvated component are observed.

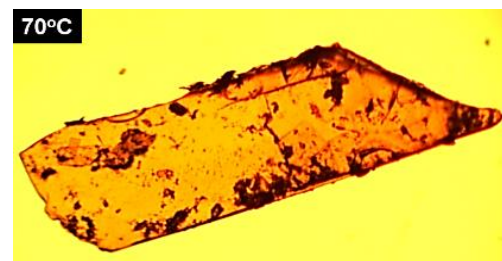

BDMC-MeOH

$77^{\circ} \mathrm{C}$

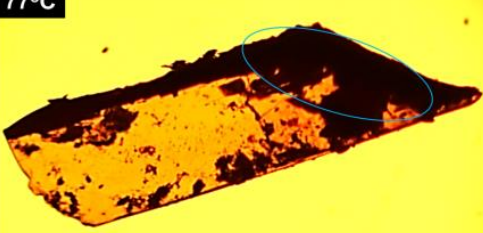

$100 \mu \mathrm{m}$

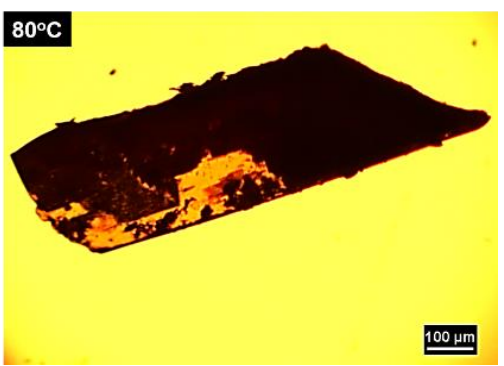

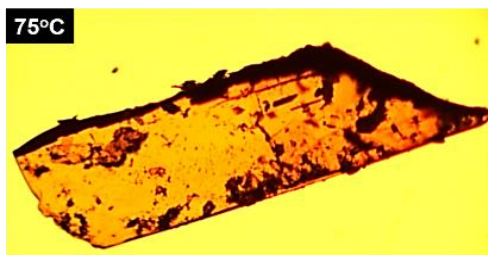

$100 \mu$

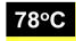

$78^{\circ} \mathrm{C}$

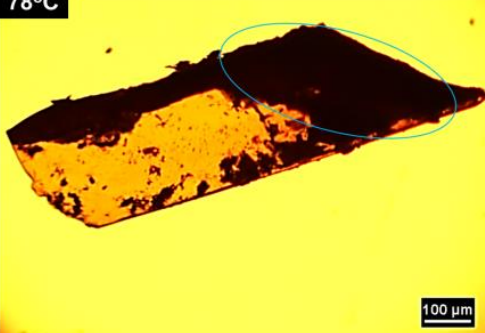

\section{$79^{\circ} \mathrm{C}$}

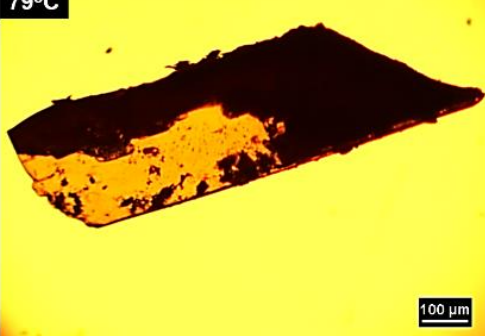

$76^{\circ} \mathrm{C}$

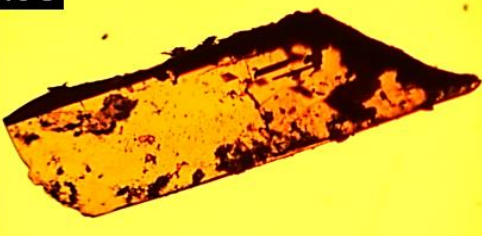

$100 \mu \mathrm{m}$ $0 \mu \mathrm{m}$

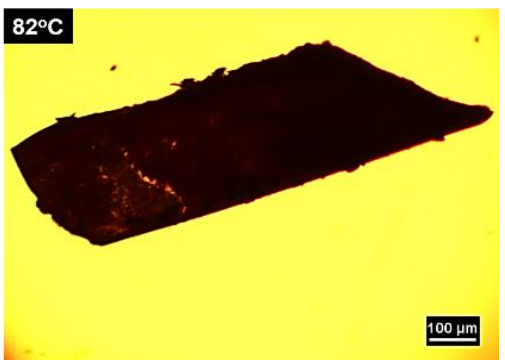


Figure 14. (b) Hot-stage microscopy (HSM) observation on the desolvation process of BDMC$\mathrm{MeOH}$ with increasing temperature at $5{ }^{\circ} \mathrm{C} \cdot \mathrm{min}^{-1}$. Several nucleation sites of the non-solvated component are observed.

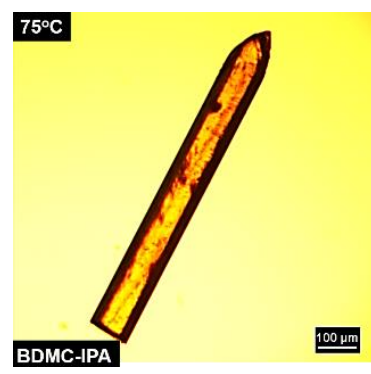

$8^{\circ 3^{\circ} \mathrm{C}}$

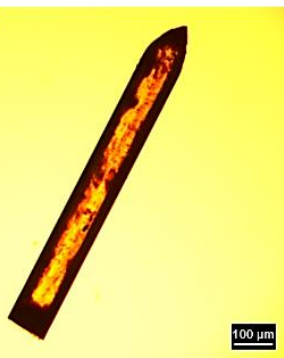

ponum

$84^{\circ} \mathrm{C}$
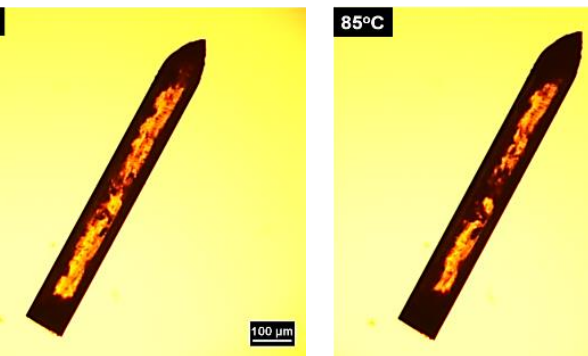

$88^{\circ} \mathrm{C}$

$87^{\circ} \mathrm{C}$
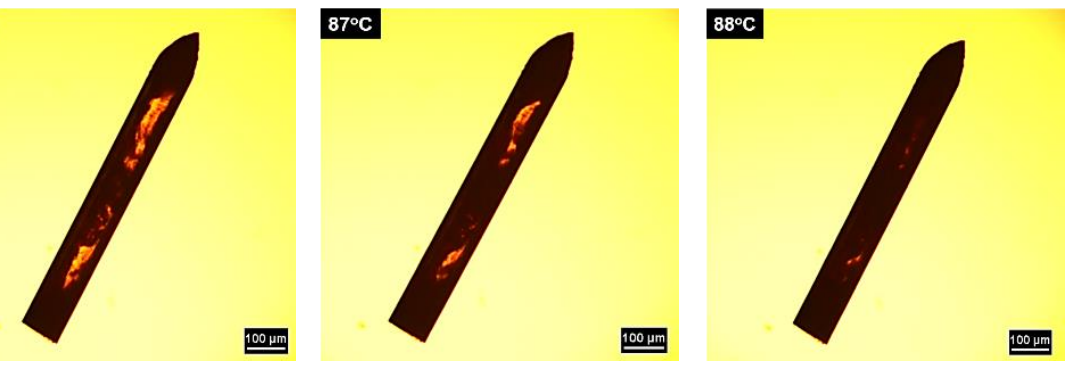

$89^{\circ} \mathrm{C}$

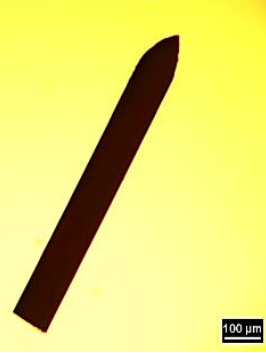

Figure 14. (c) Hot-stage microscopy (HSM) observation on the desolvation process of BDMCIPA with increasing temperature at $5{ }^{\circ} \mathrm{C} \cdot \mathrm{min}^{-1}$. Several nucleation sites of the non-solvated component are observed.

\subsubsection{Moisture Sorption and Desorption}

Moisture sorption-desorption isotherms $\left(\mathrm{T}=25^{\circ} \mathrm{C}\right)$ were performed using the dynamic vapor sorption (DVS) apparatus. Sorption studies were carried out for BDMC under acetone, methanol and isopropanol moisture by varying the partial pressure (PP) from 0 to $90 \%$ every $60 \mathrm{~min}$. Results show that no solvate was formed under the continuous moisture exposure (e.g. BDMC$\mathrm{MeOH}$, Figure SI-9). Desorption studies were performed on pre-prepared BDMC solvates (BDMC-ACET, -MeOH, -IPA), which were exposed to a varying solvent vapor from $90 \%$ to 0. 
However, no desorption was detected under the tested experimental conditions (Figure SI-10). All these results indicate that the formation of the solvated forms cannot be achieved via solidvapor equilibria. This is consistent with the fact of lacking of structural filiation between BDMC and the solvates. One can postulate that the transformation from BDMC to its solvates can only be reached via crystallization in solution.

During the study on the solid state conversion via solid-vapor equilibria, an original behavior of the methanol solvate has been highlighted. The methanol solvate stored under increasing partial pressure of acetone implies a desolvation of the initial solvated form towards the desolvated BDMC form (Figure SI-11). This result indicates that (i) the methanol solvate could desolvate under a "dry" solvent but is stable under a dry nitrogen flux, and (ii) there is no exchange of solvent in the solid state between methanol and acetone, which is consistent with the absence of similarity between the crystalline structures of methanol and acetone solvates (no mixed solvates). Moreover, BDMC obtained after desolvation does not transform under high PP of solvent, from a solid-vapor equilibria point of view, the desolvation seems irreversible.

\subsubsection{Discussion of the Desolvation Mechanism}

The mechanism of the desolvation process could be explained by the Rouen-96 model ${ }^{38}$. For BDMC-ACET and BDMC-IPA, acetone and isopropanol molecules are contained in the channels shown in Figure 10 (of sufficient size $\geq 3.5 \AA$ ), indicating that their departure is likely to occur along these channels. But the progressive release of solvent molecules produces a collapse of their crystal lattices (destructive). In the case of $\mathrm{BDMC}-\mathrm{MeOH}$, a direct destructive desolvation process occurred, i.e. a complete destruction of the crystal packing as the crystal structure is based on solvent bridges among the BDMC molecules. Moreover, the observation from microscopy (Figure 14) shows a loss of transparency of the desolvated crystals, which is 
due to the light scattering on the surface of the numerous crystallites formed. This indicates that after the destructive release of the solvent, the initial solvate recrystallizes into numerous small crystallites of the desolvated form. Therefore, a destructive-reconstructive desolvation process is postulated and this type of mechanism is corroborated by the lack of structural similarities between the solvates and the desolvated form ${ }^{39}$.

\section{CONCLUSIONS}

In summarizing the results reported here, we carried out a comprehensive study of bis(demethoxy)curcumin and its solvate formation. Pure BDMC could be obtained by crystallization from ethanol. BDMC-ACET, BDMC-MeOH and BDMC-IPA solvates were obtained by recrystallization from acetone, methanol and isopropanol, respectively. Crystal structures were determined for pure BDMC and the three solvates. In BDMC-MeOH, methanol molecules fully interact with the BDMC molecules, a strong hydrogen bonding network was formed. Moreover, a minimization of the lattice energy was achieved in BDMC-MeOH. These evidences indicate a higher stability of BDMC-MeOH compared to BDMC-ACET and BDMCIPA, which was confirmed by the desolvation and stability investigations. Thermal stability of the solvates was assessed by TGA/DSC, TR-PXRD and HSM. The weight loss from TGA was in agreement with the amount of solvent present in the crystal structure. Upon exposure to ambient conditions and elevated temperatures, $\mathrm{BDMC}-\mathrm{MeOH}$ was found to be the most stable solvate studied. Moreover, a destructive-reconstructive desolvation mechanism was proposed based on the set of data collected. No new polymorph of BDMC was formed throughout the desolvation process, but the thorough investigation of BDMC solvates is vital for industries to identify and harvest a pure solid phase. Moreover, the usage of solvate formation property might be useful for the purification of the structurally similar curcuminoids. 


\section{ACKNOWLEDGEMENT}

The authors thank Phil Liebing for updating the data of hydrogen bonds.

\section{SUPPORTING INFORMATION DESCRIPTION}

Superimposition of the BDMC molecules in the asymmetric unit of BDMC. Projection of the BDMC packing along $a, b$ and $c$ axes. Projection of the BDMC-ACET packing along $b$ and $c$ axes. Hirshfeld surface analysis of BDMC-ACET. Hirshfeld surface analysis of BDMC-MeOH. Projection of molecular chains in BDMC-IPA spreading in [011] direction. Projection of the BDMC-IPA packing along [011] ] and [011] axes. Hirshfeld surface analysis of BDMC-IPA. DVS isotherm sorption curve of BDMC under methanol vapor pressure at $25{ }^{\circ} \mathrm{C}$. DVS isotherm desorption curve of $\mathrm{BDMC}-\mathrm{MeOH}$ under methanol vapor pressure at $25{ }^{\circ} \mathrm{C}$. DVS isotherm desorption curve of BDMC-MeOH under acetone vapor pressure at $25^{\circ} \mathrm{C}$.

\section{ACCESSION CODES}

Crystallographic data including structure factors have been deposited at the CCDC. Copies of the data can be obtained free of charge on quoting the depository numbers $1867868-1867871$ via http://www.ccdc.cam.ac.uk or by e-mail deposit@ccdc.cam.ac.uk, or by contacting the Cambridge Crystallographic Data Center, 12 Union Road, Cambridge CB2 1EZ, UK; fax: +44 1223336033.

\section{AUTHOR INFORMATION}

\section{Corresponding Author}

E-mail: yuan@mpi-magdeburg.mpg.de 


\section{REFERENCES}

1. Beckmann, W. Crystallization of Pharmaceutical Compounds Polymorphs, PseudoPolymorphs and Particle Formation. Eng. Life Sci. 2003, 3, 113-120.

2. Bernstein, J. Polymorphism in Molecular Crystals; Oxford University Press: New York, 2002.

3. Ahuja, D.; Bannigan. P.; Rasmuson A. C. Study of Three Solvates of Sulfamethazine. CrystEngComm 2017, 19, 6481-6488.

4. Zvoníček, V.; Skořepová, E.; Dušek, M.; Babor, M.; Žvátora, P.; Šoóš. M. First Crystal Structures of Pharmaceutical Ibrutinib: Systematic Solvate Screening and Characterization. Cryst. Growth Des. 2017, 17, 3116-3127.

5. Griesser, U. J. In Polymorphism: in the Pharmaceutical Industry; Hilfiker, R., Ed.; WILEYVCH Verlag GmbH \& Co. KGaA: Weinheim, 2006, 211-233.

6. Surov, A. O.; Solanko, K. A.; Bond, A. D.; Bauer-Brandl, A.; Perlovich, G. L. Diversity of Felodipine Solvates: Structure and Physicochemical Properties. CrystEngComm 2015, 17, 4089-4097.

7. Maini, L.; Braga, D.; Farinella, F.; Melotto, E.; Verzini, M.; Brescello, R.; Michieletto, I.; Munari, I. Crystal Forms of Enzalutamide and a Crystal Engineering Route to Drug Purification. Cryst. Growth Des. 2018, 18, 3774-3780.

8. Wirth, D. D.; Stephenson, G. A. Purification of Dirithromycin. Impurity Reduction and Polymorph Manipulation. Org. Process Res. Dev. 1997, 1, 55-60.

9. Black, S. N.; Cuthbert, M. W.; Roberts, R. J.; Stensland, B. Increased Chemical Purity Using a Hydrate. Cryst. Growth Des. 2004, 4, 539-544. 
10. Cains, P. W. In Polymorphism in Pharmaceutical Solids; Brittain, H. G., Ed.; CRC Press: Boca Raton, 2016, 76.

11. Aitipamula, S.; Chow, P. S.; Tan, R. B. H. The Solvates of Sulfamerazine: Structural, Thermochemical, and Desolvation Studies. CrystEngComm 2012, 14, 691-699.

12. Schmidt, A. C.; Niederwanger, V.; Griesser, U. J. Solid-State Forms of Prilocaine Hydrochloride. J. Therm. Anal. Calorim. 2004, 77, 639-652.

13. Fours, B.; Cartigny, Y.; Petit, S.; Coquerel, G. Formation of New Polymorphs without Any Nucleation Step. Desolvation of the Rimonabant Monohydrate: Directional Crystallisation Concomitant to Smooth Dehydration. Faraday Discuss. 2015, 179, 475-488.

14. Tauvel, G.; Sanselme, M.; Coste-Leconte, S.; Petit, S.; Coquerel. G. Structural Studies of Several Solvated Potassium Salts of Tenatoprazole Crystallizing as Conglomerates. J. Mol. Struct. 2009, 936, 60-66.

15. Bērziņš, A.; Skarbulis, E.; Rekis, T.; Actiņš, A. On the Formation of Droperidol Solvates: Characterization of Structure and Properties. Cryst. Growth Des. 2014, 14, 2654-2664.

16. Price, C. P.; Glick, G. D.; Matzger, A. J. Dissecting the Behavior of a Promiscuous Solvate Former. Angew. Chem. 2006, 118, 2116-2120.

17. Harvey, A. L. Natural Products in Drug Discovery. Drug Discov. Today 2008, 13, 894-901.

18. Harvey, A. L. Medicines from Nature: Are Natural Products Still Relevant to Drug Discovery? Trends Pharmacol. Sci. 1999, 20, 196-198.

19. Ukrainczyk, M.; Hodnett, B. K.; Rasmuson, A. C. Process Parameters in the Purification of Curcumin by Cooling Crystallization. Org. Process Res. Dev. 2016, 20, 1593-1602. 
20. Péret-Almeida, L.; Cherubino, A. P. F.; Alves, R. J.; Dufossé, L.; Glória, M. B. A. Separation and Determination of the Physico-Chemical Characteristics of Curcumin, Demethoxycurcumin and Bisdemethoxycurcumin. Food Res. Int. 2005, 38, 1039-1044.

21. Suresh, K.; Nangia, A. Curcumin: Pharmaceutical Solids as a Platform to Improve Solubility and Bioavailability. CrystEngComm 2018, 20, 3277-3296.

22. Matlinska, M. A.; Wasylishen, R. E.; Bernard, G. M.; Terskikh, V. V.; Brinkmann, A.; Michaelis, V. K. Capturing Elusive Polymorphs of Curcumin: A Structural Characterization and Computational Study. Cryst. Growth Des. 2018, 18, 5556-5563.

23. Ruby, A. J.; Kuttan, G.; Babu, K. D.; Rajasekharan, K. N.; Kuttan, R. Anti-tumour and Antioxidant Activity of Natural Curcuminoids. Cancer Lett. 1995, 94, 79-83.

24. Syu, W.-J.; Shen, C.-C.; Don, M.-J.; Ou, J.-C.; Lee, G.-H.; Sun, C.-M. Cytotoxicity of Curcuminoids and Some Novel Compounds from Curcuma zedoaria. J. Nat. Prod. 1998, 61, $1531-1534$.

25. Poornima, B.; Prasad, K. V. S. R. G.; Bharathi, K. Evaluation of Solid-State Forms of Curcuminoids. IJPS 2016, 7, 4035-4044.

26. Karlsen, J.; Mostad, A.; Tønnesen, H. H. Structural Studies of Curcuminoids. VI. Crystal Structure of 1,7-Bis(4-hydroxyphenyl)-1,6-heptadiene-3,5-dione Hydrate. Acta Chem. Scand. B. 1988, 42, 23-27.

27. Tønnesen, H. H.; Karlsen, J.; Mostad, A.; Pedersen, U.; Rasmussen, P. B.; Lawesson, S.-O. Structural Studies of Curcuminoids. II. Crystal Structure of 1,7-Bis(4-hydroxyphenyl)-1,6heptadiene-3,5-dione Methanol Complex. Acta Chem. Scand. B. 1983, 37, 179-185. 
28. Kasai, K.; Saito, A.; Sato, S. Crystal Structure and Pseudopolymorphism of Bisdemethoxycurcumin-Alcohol Solvates. Bulletin of Miyagi University of Education 2017, $51,83-88$.

29. Chava, S.; Gorantla, S. R. A.; Muppidi, V. K. Solid Forms of Curcumin and Derivatives Thereof. WO2015052568A2, 2015.

30. Sheldrick, G. M. SHELXT-Integrated Space-Group and Crystal-Structure Determination. Acta Cryst. 2015, A71, 3-8.

31. Sheldrick, G. M. Crystal Structure Refinement with SHELXL. Acta Cryst. 2015, C71, 3-8.

32. Wolff, S. K.; Grimwood, D. J.; McKinnon, J. J.; Turner, M. J.; Jayatilaka, D.; Spackman, M. A. CrystalExplore; University of Western Australia: Crawley, Australia, 2012.

33. Renou, L.; Coste, S.; Cartigny, Y.; Petit, M.-N.; Vincent, C.; Schneider, J.-M.; Coquerel, G. Mechanism of Hydration and Dehydration of Ciclopirox Ethanolamine (1:1). Cryst. Growth Des. 2009, 9, 3918-3927.

34. Martin, A. D.; Britton, J.; Easun, T. L.; Blake, A. J.; Lewis, W.; Schröder, M. Hirshfeld Surface Investigation of Structure-Directing Interactions within Dipicolinic Acid Derivatives. Cryst. Growth Des. 2015, 15, 1697-1706.

35. Fabbiani, F. P. A.; Leech, C. K.; Shankland, K.; Johnston, A.; Fernandes, P.; Florence, A. J.; Shankland, N. Hirshfeld Surface Analysis of Two Bendroflumethiazide Solvates. Acta Cryst. 2007, C63, o659-o663.

36. Braun, D. E.; Schneeberger, A.; Griesser, U. J. Understanding the Role of Water in 1,10Phenanthroline Monohydrate. CrystEngComm 2017, 19, 6133-6145. 
37. Braun, D. E.; Gelbrich, T.; Kahlenberg, V.; Tessadri, R.; Wieser, J.; Griesser, U. J. Stability of Solvates and Packing Systematics of Nine Crystal Forms of the Antipsychotic Drug Aripiprazole. Cryst. Growth Des. 2009, 9, 1054-1065.

38. Petit, S.; Coquerel, G. Mechanism of Several Solid-Solid Transformations between Dihydrated and Anhydrous Copper (II) 8-Hydroxyquinolinates. Proposition for a Unified Model for the Dehydration of Molecular Crystals. Chem. Mater. 1996, 8, 2247-2258.

39. Amharar, Y.; Petit, S.; Sanselme, M.; Cartigny, Y.; Petit, M.-N.; Coquerel, G. Crystal Structures, Dehydration Mechanism, and Chiral Discrimination in the Solid State of a Hydantoin Derivative. Cryst. Growth Des. 2011, 11, 2453-2462. 


\section{For Table of Contents Use Only}

Solvate formation of bis(demethoxy)curcumin: Crystal structure analyses and stability investigations

Lina Yuan, ${ }^{\mathrm{a},{ }^{*}}$ Elena Horosanskaia, ${ }^{\mathrm{a}}$ Felix Engelhardt, ${ }^{\mathrm{b}}$ Frank T. Edelmann, ${ }^{\mathrm{b}}$ Nicolas Couvrat, ${ }^{\mathrm{c}}$ Morgane Sanselme, ${ }^{\mathrm{c}}$ Yohann Cartigny, ${ }^{\mathrm{c}}$ Gérard Coquerel, ${ }^{\mathrm{c}}$ Andreas Seidel-Morgenstern, ${ }^{\mathrm{a}}$ and Heike Lorenz ${ }^{\mathrm{a}}$

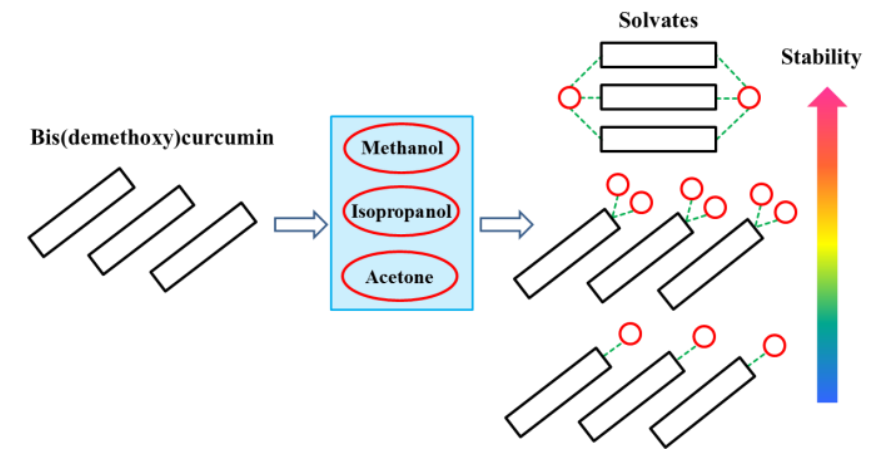

Three solvates of bis(demethoxy)curcumin were obtained by recrystallization from methanol, isopropanol and acetone. Their crystal structures were resolved by single crystal X-ray diffraction and the desolvation processes were analyzed by various techniques. The solvate obtained from methanol shows the most efficient hydrogen bonding and the highest stability at ambient and elevated temperatures. 